\title{
General dislocation image stress of anisotropic cubic thin film
}

\author{
Wenwang Wu, ${ }^{1}$ Robin Schäublin, ${ }^{2}$ and Jiachao Chen ${ }^{1, a)}$ \\ ${ }^{1}$ Department of Nuclear Energy and Safety, Paul Scherrer Institute, 5232 Villigen PSI, Switzerland \\ ${ }^{2}$ Ecole Polytechnique Fédérale de Lausanne (EPFL), Centre de Recherches en Physique des Plasmas, \\ Association Euratom-Confédération Suisse, 5232 Villigen PSI, Switzerland
}

(Received 31 August 2012; accepted 12 October 2012; published online 12 November 2012)

\begin{abstract}
A calculation method for accurately computing the displacement, image stress, and image energy induced by defects, such as cavities, precipitates, finite dislocation segments, and dislocation loops, in a free-standing anisotropic thin crystal film is presented. The anisotropic image stress is derived in the Fourier space from the standing Christoffel stress equilibrium equation for anisotropic materials, relying on the elastic parameters, the crystallographic orientation of the film and the considered defect. The image stress corresponds to the traction stress field, describing the stress field at the free surface. The latter is the stress induced by the same defects in an infinite medium evaluated at the location of the free surface. This method is applied to pure bcc Fe semi infinite single crystals and thin crystal films. The calculation results show that a stronger image stress induced in-plane and out-of plane displacement difference is produced with the anisotropic elasticity for bcc $\mathrm{Fe}$, relative to the isotropic case, calculated by either Voigt or Reuss methods. It confirms that anisotropy has a strong influence on the image stress induced 3D displacement fields. (C) 2012 American Institute of Physics. [http://dx.doi.org/10.1063/1.4764341]
\end{abstract}

\section{INTRODUCTION}

Accounting for the effects of free surfaces on the physical properties of defects in thin crystal films is important, as the ratio of surface to volume is high. In effect, earlier calculations $^{1-3}$ of the corresponding image displacement and stress fields induced by the free surfaces show that when the specific size of defects is comparable to the thickness of the thin film, their interaction with free surfaces cannot be neglected anymore. It implies that the dislocation behavior in thin films is significantly different from that in a corresponding infinite medium, and the mechanical and physical properties of the thin film are also changed. Dislocation dynamics (DD) for dimensionally restricted materials should also include surface effects. ${ }^{4-6}$ The total elastic energy of a dislocation loop within thin film is influenced by not only the film thickness, but also by its relative crystallographic orientation, depending on the loop's Burgers vectors, habit plane, and location in the film.

There are several methods available in the literature for dealing with the surface image stress effect, but these methods are mainly dealing with dislocations within isotropic materials and use the classical image method, as described later. These models include (1) classical image dislocation in semi infinite space $^{7}$ and half-space Peierls-Nabarro (HSPN) model for screw/edge dislocations; ${ }^{8,9}$ (2) infinite image dislocation series in thin film; ${ }^{10}$ (3) average image stresses of defects by TanakaMori-Mura method; ${ }^{11}$ (4) Lothe's energy theorem; ${ }^{12}$ (5) Gosling and Willis' Green's function method; ${ }^{13,14}$ and (6) the superposition method based on solution of the Boussinesq problem. ${ }^{10,14}$ The classical image stress methods consist basically of superposing firstly an image dislocation beyond the free surface, and of devising secondly a stress function that will

\footnotetext{
${ }^{\text {a) }}$ Author to whom correspondence should be addressed. E-mail: jiachao. chen@psi.ch. Tel.: +41 5631022 80. Fax: +41 563104595.
}

cancel the remaining shear and normal stress $\left(\sigma_{x z}, \sigma_{y z}, \sigma_{z z}\right)$ acting at the surface, thus, satisfying the free surface condition. For complex dislocation configurations and boundary conditions, the image stress due to free surfaces and interfaces can now, owing to computing power, be computed by finite element method. ${ }^{15-18}$ Weinberger et al. ${ }^{19}$ calculated the image energy using the basic solution for isotropic materials.

However, most crystals are anisotropic, and the anisotropic ratio changes with environment physical parameters, such as the temperature, moisture, electron field, magnetic field, etc. A theorem based on anisotropic Stroh's formula for calculating the image stress of infinite straight dislocations in anisotropic bicrystals has been developed by Barnett and Lothe,$^{20}$ which was further deployed for the elastic field calculation of dislocations emerging at the free surface of semi infinite crystals. ${ }^{21}$ It was thus necessary to have a corresponding general theoretical solution to the image displacement, image stress fields, and image energy in anisotropic thin films, a task we have undertaken.

In this paper, efficient numerical algorithms in Fourier space to compute the corresponding image displacement, strain, stress field induced by defects in semi infinite crystals, and free-standing anisotropic thin crystal films are presented. The method is then applied to analyze the image stress effect induced by nanometric dislocation loops in pure bcc Fe semi infinite single crystals and thin films. The calculation results show that a stronger image stress induced in-plane and out-of plane displacement difference is produced in anisotropic bcc $\mathrm{Fe}$, relative to the isotropic case, calculated by $\mathrm{Voigt}^{22}$ or Reuss $^{23}$ methods. It shows that the anisotropic ratio has a strong influence on the image stress induced 3D displacement fields.

In order to describe the theory systematically, the article is presented in 3 parts, namely, (1) the basic cubic crystal with $\langle 001\rangle$ orientation, (2) the general crystal with arbitrary orientation, (3) calculation examples of bcc Fe containing a nanometric dislocation loop, ending with a comparison of 
the image stress induced displacement field between Voigt isotropic and anisotropic methods.

\section{THE IMAGE STRESS IN ANISOTROPIC SEMI INFINITE CRYSTAL AND THIN FILM}

\section{A. General description of the method}

The total stress field $\left(\sigma_{i j}^{t o t}\right)$ of a dislocation within a semi infinite crystal can be treated as two superimposed stress fields: the infinite stress field $\left(\sigma_{i j}^{\infty}\right)$ induced by the same defect in an infinite crystal and the image stress field $\left(\sigma_{i j}^{i m g}\right)$ induced by the presence of the free surface. The total stress inside the semi infinite crystal can then be written as the superposition of the two stress fields (see Fig. 1)

$$
\sigma_{i j}^{t o t}=\sigma_{i j}^{\infty}+\sigma_{i j}^{i m g} .
$$

The stress field $\left(\sigma_{i j}^{\infty}\right)$ of different kinds of defects, such as He bubbles, precipitates, threading dislocation segments, and dislocation loops, in anisotropic infinite crystal materials is well known. In this article, only dislocation segments and dislocation loops are considered.

The stress field of a dislocation loop $C^{\prime}$ in an infinite medium is given by Mura formulas: ${ }^{24}$

$$
\sigma_{i j}(x)=C_{i j k l} \oint_{C^{\prime}} \varepsilon_{\ln h} C_{p q m n} G_{k p, q}\left(x-x^{\prime}\right) b_{m}^{\prime} d x_{h}^{\prime} .
$$

The line integral is performed with respect to $x_{h}^{\prime}$ along the dislocation line $C^{\prime}, \mathrm{G}_{k p}$ are the Green's functions for anisotropic crystals, $C_{i j k l}$ are the elastic constants, and $b_{m}^{\prime}$ is the Burgers vector of dislocation loop $C^{\prime}$.

The stress field of a finite dislocation segment in an infinite anisotropic medium is given by Brown's formula or the Willis-Steeds-Lothe formula: ${ }^{25}$

$$
\sigma_{i j}=\left.\frac{1}{2 d}\left[-\cos (\theta-\alpha) \sum_{i j}(\theta)+\sin (\theta-\alpha) \sum_{i j}^{\prime}(\theta)\right]\right|_{\theta_{1}} ^{\theta_{2}} .
$$

Consider a plane containing the straight segment $A B$ and the end point $P . \alpha$ is the angle between the segment $A B$ and an arbitrary (but fixed) datum in the same plane. $\theta_{1}$ and $\theta_{2}$ measure the orientations of line $A P$ and line $B P$, relative to the datum, respectively. $\sum_{i j}(\theta)$ is the angular stress factor of an infinite straight dislocation along $A P$ or $B P . \sum_{i j}^{\prime}(\theta)$ is its derivative with respect to the angle $\theta$.
Given the geometrical and physical parameters of the defect and of the host crystal, the corresponding stress $\left(\sigma_{i j}^{\infty}\right)$ in the infinite medium at the free surface position can be calculated with Eq. (2) or Eq. (3). The resulting stress field in the infinite medium is then employed for calculating the resultant image displacement, strain, and stress field, as described in the following.

Considering the fact that the total traction stress component $\left(\sigma_{x z}^{t o t}, \sigma_{y z}^{t o t}, \sigma_{z z}^{t o t}\right)$ should be zero at free surface position, the corresponding image stress $\left(\sigma_{x z}^{i m g}, \sigma_{y z}^{i m g}, \sigma_{z z}^{i m g}\right)$ in Eq. (1) can be produced and written in the Fourier space

$$
\sigma_{i j}^{i m g}=\sum_{k_{x}} \sum_{k_{y}} \sigma_{\left(k_{x}, k_{y}\right)}^{*} \cdot \exp \left(i k_{x} x+i k_{y} y\right)(j=1,2,3) .
$$

Due to the completeness of Fourier series, the corresponding image displacement field satisfying the equilibrium of the film, that is to say the restriction to $(\mathrm{x}, \mathrm{y})$ space, can be written as a superposition of the general solutions written in Fourier space, each with a different $k_{x}$ and $k_{y}$.

For convenience, the image displacement field in Fourier space can be written as

$$
\begin{aligned}
u(x, y, z)= & \sum_{k_{x}} \sum_{k_{y}}\left[\hat{u}^{+}\left(k_{x}, k_{y}, z\right)+\hat{u}^{-}\left(k_{x}, k_{y}, z\right)\right] \\
& \times \exp \left(i k_{x} x+i k_{y} y\right) .
\end{aligned}
$$

Then, the image stress field can be obtained from the anisotropic Hook's law

$$
\begin{aligned}
\sigma(x, y, z)= & \sum_{k_{x}} \sum_{k_{y}}\left[\hat{\sigma}^{+}\left(k_{x}, k_{y}, z\right)+\hat{\sigma}^{-}\left(k_{x}, k_{y}, z\right)\right] \\
& \times \exp \left(i k_{x} x+i k_{y} y\right) .
\end{aligned}
$$

The unknown coefficients $\hat{u}\left(k_{x}, k_{y}, z\right)$ and $\hat{\sigma}\left(k_{x}, k_{y}, z\right)$ are described as a function of the single parameter $z$, and the corresponding coefficients can be calculated out by matching the image stress field $\left(\hat{\sigma}_{x z}, \hat{\sigma}_{y z}, \hat{\sigma}_{z z}\right)$ at the free surface position $z=z_{0}$ for each Fourier mode between Eqs. (4) and (6), thus, producing the final image displacement, strain and stress field at arbitrary position $z$ within the medium.

The numerical algorithm for doing this in a semi infinite crystal and crystal thin film is elaborated in the following subsections. Both semi infinite crystal and crystal thin film are considered to be periodic in both $\mathrm{x}$ and $\mathrm{y}$ directions, with periodic length $L_{x}$ and $L_{y}$, respectively. The wave number in Fourier space is described as $k_{x}=2 \pi n_{x} / L_{x}$ and $k_{y}=2 \pi n_{y} / L_{y}$, where $n_{x}, n_{y}=0, \pm 1,2, \ldots$
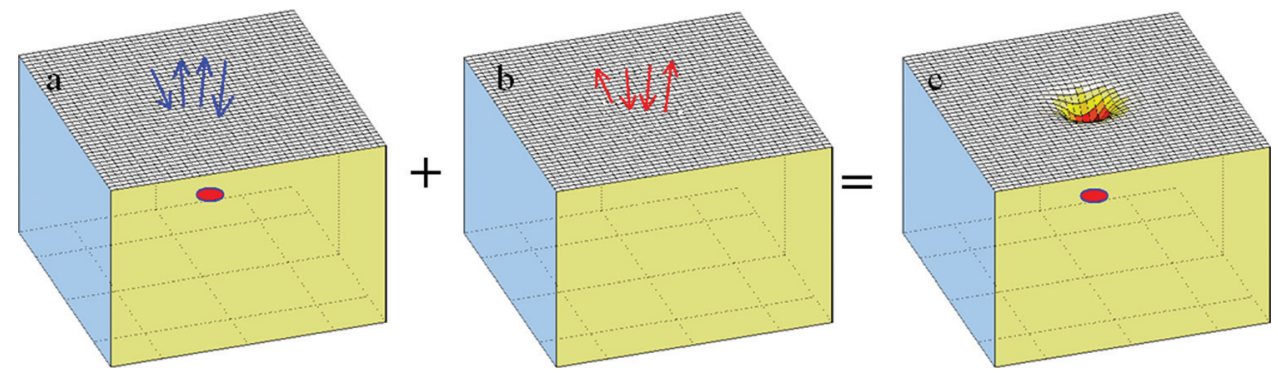

FIG. 1. Schematics of the procedure to devise the image stress of a defect in a crystal (pink disk in the center) due to the presence of a free surface. (a) Traction forces $\sigma_{i j}^{\infty}$ at the free surface position in the infinite crystal. (b) Image stress $\sigma_{i j}^{i m g}$ introduced to cancel the traction stress. (c) The total stress field in the semi infinite crystal is $\sigma_{i j}^{t o t}=\sigma_{i j}^{\infty}=\sigma_{i j}^{i m g}$ and the resulting displacement field is visible as a dimple in the surface. 


\section{B. The image stress of cubic crystals}

In the absence of body forces, the stress equilibrium equation given by the standing Christoffel equation ${ }^{26}$ for cubic material with a free surface orientation of the type $\langle 100\rangle$ can be written in terms of the displacement field $(u, v, w)$ as

$$
\left\{\begin{aligned}
C_{12}\left(u_{x x}+v_{y x}+w_{z x}\right)+\left(C_{11}-C_{12}\right) u_{x x}+C_{44}\left(u_{y y}+v_{x y}\right)+C_{44}\left(u_{z z}+v_{x z}\right) & =0 \\
C_{12}\left(u_{x y}+v_{y y}+w_{z y}\right)+\left(C_{11}-C_{12}\right) v_{y y}+C_{44}\left(u_{y x}+v_{x x}\right)+C_{44}\left(v_{z z}+w_{y z}\right) & =0 \\
C_{12}\left(u_{x z}+v_{y z}+w_{z z}\right)+\left(C_{11}-C_{12}\right) w_{z z}+C_{44}\left(w_{x x}+u_{z x}\right)+C_{44}\left(v_{z y}+w_{y y}\right) & =0 .
\end{aligned}\right.
$$

According to the basic properties of cubic crystal, the elastic energy should be larger than zero and the determinant of the stiffness matrix should be positive, thus, producing the following conditions:

$$
\left\{\begin{array}{l}
C_{11}-C_{12}>0 \\
C_{11}-2 C_{12}>0
\end{array}\right.
$$

\section{Lower semi infinite space}

Let $z$ direction be perpendicular to the $(x, y)$ film plane and consider an elastic semi infinite space that occupies the region $z \leq 0$. The following solution to these 3 coupled equations (7) is periodic in the $\mathrm{x}$ and $\mathrm{y}$ directions, and exponential in the $\mathrm{z}$ direction. Indeed, for the solution to be bounded for $z \rightarrow-\infty$, the function of $z$ is assumed to be of the type $e^{+\mathrm{qz}}$ in Eq. (5). The displacement modes are described as standing surface waves. Hence

$$
\begin{aligned}
(u, v, w)= & \sum_{k_{x}} \sum_{k_{y}}\left(U\left(k_{x}, k_{y}\right), V\left(k_{x}, k_{y}\right), W\left(k_{x}, k_{y}\right)\right) \\
& \times \exp \left(i k_{x} x+i k_{y} y+q \cdot z\right) .
\end{aligned}
$$

In which, $(u, v, w)$ are the displacement field along $(x, y, z)$ direction. The parameters $\left(U\left(k_{x}, k_{y}\right), V\left(k_{x}, k_{y}\right), W\left(k_{x}, k_{y}\right)\right)$ are complex constants for each Fourier mode $\left(k_{x}, k_{y}\right)$, the displacement components are written in terms of complex exponentials. In the end, only the real parts of the solution are retained for the solution. The real parts of the corresponding roots $q$ should be larger than zero for the lower semi infinite space.

By placing the displacement field (9) into the equilibrium equation (7), one obtains the following equations for each Fourier mode:

$$
\left(\begin{array}{ccc}
\left(q^{2} C_{44}-k_{x}^{2} C_{11}-k_{y}^{2} C_{44}\right) & -k_{x} k_{y}\left(C_{12}+C_{44}\right) & i k_{x} q\left(C_{12}+C_{44}\right) \\
-k_{x} k_{y}\left(C_{12}+C_{44}\right) & \left(q^{2} C_{44}-k_{y}^{2} C_{11}-k_{x}^{2} C_{44}\right) & i k_{y} q\left(C_{12}+C_{44}\right) \\
i k_{x} q\left(C_{12}+C_{44}\right) & i k_{y} q\left(C_{12}+C_{44}\right) & \left(q^{2} C_{11}+k_{x}^{2} C_{44}-k_{y}^{2} C_{44}\right)
\end{array}\right) \cdot\left(\begin{array}{c}
U \\
V \\
W
\end{array}\right)=0 .
$$

The condition that non-zero roots exist requires that the determinant of the coefficients matrix of Eq. (10) is zero, and the descriminant of the cubic matrix will be used for judging the physical properties of the attenuation factor $q$. Depending on the properties of $q$, the displacement fields $(u, v, w)$ are described as a composition of Rayleigh-type waves, an exponentially decaying function, generalized Rayleigh-type waves, the product of a trigonometric function and an exponentially decaying function, or Love-type waves, perpendicular to the sagittal plane for standing Rayleigh waves propagation. One can distinguish several deformation modes, depending on an arbitrary choice for $\mathrm{kx}$ and $\mathrm{ky}$, as described in the following.

(a) $\operatorname{Mode}\left(k_{\mathrm{x}} \neq 0, k_{y} \neq 0\right)$

When the determinant of the coefficient matrix in Eq. (10) is zero, a sextic equation in $q$ is produced, which has in general three desired roots with positive real parts. Depending on the attenuation coefficient properties of the three $q_{j}$, the ratios of the corresponding
$\left(U_{j}, V_{j}, W_{j}\right)$ are calculable. After performing the cofactor expansion along the first row of the matrix in Eq. (10), the corresponding $\left(\xi_{j}, \eta_{j}, \zeta_{j}\right)$ are the elements along the first row of the cofactor expansion matrix in Eq. (10).

$$
\frac{U_{j}}{\xi_{j}}=\frac{V_{j}}{\eta_{j}}=\frac{W_{j}}{\zeta_{j}}=K_{j} ; \quad(j=1,2,3),
$$

the resultant $\left(\xi_{j}, \eta_{j}, \zeta_{j}\right)$ is described in Appendix A.

(b) Mode $\left(k_{x}=0, k_{y} \neq 0\right)$

The determinant of the matrix in Eq. (10) can be reduced into the product of two sub-determinants, which will produce 3 roots: $q_{1}=\left|k_{y}\right|$, and $\left(q_{2}, q_{3}\right)$ are the roots (with positive real parts) of the following equation.

$$
\begin{aligned}
& C_{44} C_{11} \cdot q_{j}^{4}+\left(C_{12} C_{12}+2 C_{12} C_{44}-C_{11} C_{11}\right) k_{y}^{2} \cdot q_{j}^{2} \\
& \quad+k_{y}^{4} C_{44} C_{11}=0 ; \quad(j=2,3) .
\end{aligned}
$$

The attenuation constants of the two superimposed waves are obtained from the quadratic equation (12), 
and a transition from Rayleigh-type to generalized Rayleigh-type waves will occur when the two roots change from positive real to complex roots (with positive real parts). The condition of the transition is obtained by setting the determinant equal to zero, thus, getting the transition boundary conditions

$$
C_{12}+2 C_{44}-C_{11}=0 .
$$

(c) Mode $\left(k_{x} \neq 0, k_{y}=0\right)$

Similar to the $\left(k_{x}=0, k_{y} \neq 0\right)$ mode, the determinant can be reduced into the product of two sub-determinants, which will produce 3 roots: $q_{1}=\left|k_{y}\right|$, and $\left(q_{2}, q_{3}\right)$ are the roots (with positive real parts) of the following equation:

$$
\begin{aligned}
& C_{44} C_{11} \cdot q_{j}^{4}+\left(C_{12} C_{12}+2 C_{12} C_{44}-C_{11} C_{11}\right) k_{x}^{2} \cdot q_{j}^{2} \\
& \quad+k_{x}^{4} C_{44} C_{11}=0 ; \quad(j=2,3) .
\end{aligned}
$$

(d) Mode $\left(k_{x}=0, k_{y}=0\right)$

The mode $\left(k_{x}=0, k_{y}=0\right)$ means constant force and displacement fields. This leads to uniform stress within semi-infinite space. Physically, a dislocation will not be able to exert a constant traction in the semi-infinite space. The $\left(k_{x}=0, k_{y}=0\right)$ mode is thus avoided.

After getting all modes for the Fourier analysis in (a)-(d), the displacement components are related with the coefficients $\left(K_{1}, K_{2}, K_{3}\right)$ as follows:

$$
\left(\begin{array}{c}
\hat{\bar{u}} \\
\hat{\bar{v}} \\
\hat{\bar{w}}
\end{array}\right)=\left[N^{-}\right] \cdot\left(\begin{array}{l}
K_{1} \\
K_{2} \\
K_{3}
\end{array}\right)
$$

The resultant $\left[\mathrm{N}^{-}\right]$is described in Appendix A. From the displacement field in Eq. (15), it is straightforward to obtain the strain field $\varepsilon_{i j}$ through differentiation and the stress field $\sigma_{i j}$ using Hooke's law. The corresponding tractions composed of the stress components $\left(\sigma_{x z}, \sigma_{y z}, \sigma_{z z}\right)$ on the surface $z=0$ are composed of the coefficients $\left(K_{1}, K_{2}, K_{3}\right)$ through the matrix equation:

$$
\left(\begin{array}{c}
\hat{T}_{x z} \\
\hat{T}_{y z} \\
\hat{T}_{z z}
\end{array}\right)=\left[M^{-}\right] \cdot\left(\begin{array}{c}
K_{1} \\
K_{2} \\
K_{3}
\end{array}\right)
$$

The resultant $\left[\mathrm{M}^{-}\right]$is described in Appendix A. Given the surface traction $\left(\hat{T}_{x z}, \hat{T}_{y z}, \hat{T}_{z z}\right)$ produced by dislocation loop in infinite media at the film surface position, the Fourier coefficients $\left(K_{1}, K_{2}, K_{3}\right)$ of any Fourier Mode $\left(k_{x}, k_{y}\right)$ can be determined from these relationships. Once the Fourier coefficients are obtained, the displacement, stress field of this Fourier mode is completely determined through the Fourier analytic expressions.

\section{Upper semi infinite space}

In preparation for the thin film elasticity described later, we need to consider an elastic semi infinite space that occupies the region $z \geq 0$. For the solution to be bounded for $z \rightarrow+\infty$, an exponential displacement field in the form of $e^{-q \cdot z}$ is employed. The displacement modes are again described as standing surface waves, hence

$$
\begin{aligned}
(u, v, w)= & \sum_{k_{x}} \sum_{k_{y}}\left(U\left(k_{x}, k_{y}\right), V\left(k_{x}, k_{y}\right), W\left(k_{x}, k_{y}\right)\right) \\
& \times \exp \left(i k_{x} x+i k_{y} y-q \cdot z\right) .
\end{aligned}
$$

Submitting Eq. (17) into the equilibrium equation (7), the following equation is derived:

$$
\left(\begin{array}{ccc}
\left(q^{2} C_{44}-k_{x}^{2} C_{11}-k_{y}^{2} C_{44}\right) & -k_{x} k_{y}\left(C_{12}+C_{44}\right) & -i k_{x} q\left(C_{12}+C_{44}\right) \\
-k_{x} k_{y}\left(C_{12}+C_{44}\right) & \left(q^{2} C_{44}-k_{y}^{2} C_{11}-k_{x}^{2} C_{44}\right) & -i k_{y} q\left(C_{12}+C_{44}\right) \\
-i k_{x} q\left(C_{12}+C_{44}\right) & -i k_{y} q\left(C_{12}+C_{44}\right) & \left(q^{2} C_{11}-k_{x}^{2} C_{44}-k_{y}^{2} C_{44}\right)
\end{array}\right) \cdot\left(\begin{array}{c}
U \\
V \\
W
\end{array}\right)=0 .
$$

Following the same development as for the lower semi infinite space, resulting in Eqs. (8)-(16), the resultant $\left(\xi_{j}, \eta_{j}, \zeta_{j}\right),\left[N^{+}\right]$, and $\left[M^{+}\right]$are obtained, which are described in Appendix B.

\section{Thin film}

The thin film is assumed to have a thickness of $2 t$ in the $z$ direction and is periodic along $\mathrm{x}$ and $\mathrm{y}$ directions.

The solution of the equilibrium equation in a free-standing thin film $(-t<z<t)$ must contain both $e^{+q \cdot z}$ and $e^{-q \cdot z}$ terms to satisfy the bounding conditions. The displacement fields of Eq. (5) can be further written with sinus hyperbolic und cosine hyperbolic forms:

$$
\left\{\begin{aligned}
u & =\sum_{k_{x}} \sum_{k_{y}}\left[U^{S} \sinh \left(q^{S} z\right)+U^{A} \cosh \left(q^{A} z\right)\right] \cdot \exp \left(i k_{x} x+i k_{y} y\right), \\
v & =\sum_{k_{x}} \sum_{k_{y}}\left[V^{S} \sinh \left(q^{S} z\right)+V^{A} \cosh \left(q^{A} z\right)\right] \cdot \exp \left(i k_{x} x+i k_{y} y\right), \\
w & =\sum_{k_{x}} \sum_{k_{y}}^{{ }^{S}}\left[W^{S} \cosh \left(q^{S} z\right)+W^{A} \sinh \left(q^{A} z\right)\right] \cdot \exp \left(i k_{x} x+i k_{y} y\right) .
\end{aligned}\right.
$$

By placing the displacement formulas (19) into the equilibrium equation (7), the equilibrium equations at the position $\pm z$ can be converted into two independent sets of equations, in which $\left(U^{S}, V^{S}, W^{S}\right)$ corresponds to the symmetrical parts, and $\left(U^{A}, V^{A}, W^{A}\right)$ corresponds to the asymmetrical parts, respectively. 
As to the symmetrical solution part, the matrix equation is as follows:

$$
\left(\begin{array}{ccc}
\left(\left(q^{S}\right)^{2} C_{44}-k_{x}^{2} C_{11}-k_{y}^{2} C_{44}\right) & -k_{x} k_{y}\left(C_{12}+C_{44}\right) & i k_{x} q^{S}\left(C_{12}+C_{44}\right) \\
-k_{x} k_{y}\left(C_{12}+C_{44}\right) & \left(\left(q^{S}\right)^{2} C_{44}-k_{y}^{2} C_{11}-k_{x}^{2} C_{44}\right) & i k_{y} q^{S}\left(C_{12}+C_{44}\right) \\
i k_{x} q^{S}\left(C_{12}+C_{44}\right) & i k_{y} q^{S}\left(C_{12}+C_{44}\right) & \left(\left(q^{S}\right)^{2} C_{11}-k_{x}^{2} C_{44}-k_{y}^{2} C_{44}\right)
\end{array}\right)\left(\begin{array}{c}
U^{S} \\
V^{S} \\
W^{S}
\end{array}\right)=0 .
$$

As to the asymmetrical solution part, the matrix equation is as follows:

$$
\left(\begin{array}{ccc}
\left(\left(q^{A}\right)^{2} C_{44}-k_{x}^{2} C_{11}-k_{y}^{2} C_{44}\right) & -k_{x} k_{y}\left(C_{12}+C_{44}\right) & i k_{x} q^{A}\left(C_{12}+C_{44}\right) \\
-k_{x} k_{y}\left(C_{12}+C_{44}\right) & \left(\left(q^{A}\right)^{2} C_{44}-k_{y}^{2} C_{11}-k_{x}^{2} C_{44}\right) & i k_{y} q^{A}\left(C_{12}+C_{44}\right) \\
i k_{x} q^{A}\left(C_{12}+C_{44}\right) & i k_{y} q^{A}\left(C_{12}+C_{44}\right) & \left(\left(q^{A}\right)^{2} C_{11}-k_{x}^{2} C_{44}-k_{y}^{2} C_{44}\right)
\end{array}\right)\left(\begin{array}{c}
U^{A} \\
V^{A} \\
W^{A}
\end{array}\right)=0 .
$$

As for the semi infinite space we are left with the arbitrary choice for $\mathrm{kx}$ and $\mathrm{ky}$, which defines several modes described in the following.

(a) $\operatorname{Mode}\left(k_{x} \neq 0, k_{y} \neq 0\right)$

When the determinant of the coefficient matrix in Eq. (20) is zero, 3 desired roots $\left(q_{1}^{S}, q_{2}^{S}, q_{3}^{S}\right)$ with positive real parts will be produced. After doing the cofactor expansion along the first row of the coefficient matrix, the corresponding $\left(\xi_{j}^{S}, \eta_{j}^{S}, \zeta_{j}^{S}\right)$ elements along the first row of the cofactor expansion matrix can be calculated out. The ratios of the corresponding $\left(U_{j}^{S}, V_{j}^{S}, W_{j}^{S}\right)$ are calculable, which can be written as

$$
\frac{U_{j}^{S}}{\xi_{j}^{S}}=\frac{V_{j}^{S}}{\eta_{j}^{S}}=\frac{W_{j}^{S}}{\zeta_{j}^{S}}=K_{j}^{S} ; \quad(j=1,2,3) .
$$

The resultant $\left(\xi_{j}^{S}, \eta_{j}^{S}, \zeta_{j}^{S}\right)$ is described in Appendix C.

When the determinant of the coefficient matrix in Eq. (21) is zero, 3 desired roots $\left(q_{1}^{A}, q_{2}^{A}, q_{3}^{A}\right)$ with positive real parts will be produced. After doing the cofactor expansion along the first row of the coefficient matrix, the corresponding $\left(\xi_{j}^{A}, \eta_{j}^{A}, \zeta_{j}^{A}\right)$ elements along the first row of the cofactor expansion matrix can be calculated out. The ratios of the corresponding $\left(U_{j}^{A}, V_{j}^{A}, W_{j}^{A}\right)$ are calculable, which can be written as

$$
\frac{U_{i}^{A}}{\xi_{i}^{A}}=\frac{V_{i}^{A}}{\eta_{i}^{A}}=\frac{W_{i}^{A}}{\zeta_{i}^{A}}=K_{i}^{A} .
$$

The resultant $\left(\xi_{i}^{A}, \eta_{i}^{A}, \zeta_{i}^{A}\right)$ is described in Appendix C.

(b) Mode $\left(k_{x}=0, k_{y} \neq 0\right)$

The determinant can be reduced into the product of two sub-determinants.

For the symmetrical part, this equation set has three roots: $q_{1}^{S}=\left|k_{y}\right|$ and $\left(q_{2}^{S}, q_{3}^{S}\right)$ are the roots (with positive real parts) of the following equation:

$$
\begin{gathered}
C_{11} C_{44} \cdot\left(q_{j}^{S}\right)^{4}+\left(C_{12} C_{12}-C_{11} C_{11}+2 C_{12} C_{44}\right) k_{y}^{2} \\
\cdot\left(q_{j}^{S}\right)^{2}+k_{y}^{4} C_{44} C_{11}=0 ; \quad(j=2,3) .
\end{gathered}
$$

For the asymmetrical part, this equation set has the roots: $q_{1}^{A}=\left|k_{y}\right|$ and $\left(q_{2}^{A}, q_{3}^{A}\right)$ are the roots (with positive real parts) of the following equation:

$$
\begin{aligned}
& C_{11} C_{44} \cdot\left(q_{j}^{A}\right)^{4}+\left(C_{12} C_{12}-C_{11} C_{11}+2 C_{12} C_{44}\right) k_{y}^{2} \cdot\left(q_{j}^{A}\right)^{2} \\
& \quad+k_{y}^{4} C_{44} C_{11}=0 ; \quad(j=2,3) .
\end{aligned}
$$

(c) Mode $\left(k_{x} \neq 0, k_{y}=0\right)$

The determinant can be reduced into the product of two sub-determinants.

For the symmetrical parts, this equation set has the roots: $q_{1}^{S}=\left|k_{x}\right|$ and $\left(q_{2}^{S}, q_{3}^{S}\right)$ are the roots (with positive real parts) of the following equation:

$$
\begin{aligned}
& C_{11} C_{44} \cdot\left(q_{j}^{S}\right)^{4}+\left(C_{12} C_{12}-C_{11} C_{11}+2 C_{12} C_{44}\right) k_{x}^{2} \cdot\left(q_{j}^{S}\right)^{2} \\
& \quad+k_{x}^{4} C_{44} C_{11}=0 ; \quad(j=2,3) .
\end{aligned}
$$

For the asymmetrical parts, this equation set has the roots: $q_{1}^{A}=\left|k_{x}\right|$, and $\left(q_{2}^{A}, q_{3}^{A}\right)$ are the roots (with positive real parts) of the following equation:

$$
\begin{aligned}
& C_{11} C_{44} \cdot\left(q_{j}^{A}\right)^{4}+\left(C_{12} C_{12}-C_{11} C_{11}+2 C_{12} C_{44}\right) k_{x}^{2}\left(q_{j}^{A}\right)^{2} \\
& \quad+k_{y}^{4} C_{44} C_{11}=0 ; \quad(j=2,3) .
\end{aligned}
$$

(d) Mode $\left(k_{x}=0, k_{y}=0\right)$

The mode $\left(k_{x}=0, k_{y}=0\right)$ means constant force and displacement fields. This leads to uniform stress inside the thin film. Physically, a dislocation will not be able to exert a constant traction stress field on the free surface. The $\left(k_{x}=0, k_{y}=0\right)$ mode is thus avoided.

The traction forces on the top and bottom surfaces are $\hat{T}^{+}=\left(\hat{T}_{x z}^{+}, \hat{T}_{y z}^{+}, \hat{T}_{z z}^{+}\right)$and $\hat{T}^{-}=\left(\hat{T}_{x z}^{-}, \hat{T}_{y z}^{-}, \hat{T}_{z z}^{-}\right)$, respectively. Likewise, the displacements are $\hat{\bar{u}}^{+}=\left(\hat{\bar{u}}^{+}, \hat{\bar{v}}^{+}, \hat{\bar{w}}^{+}\right)$and $\hat{\bar{u}}^{-}=\left(\hat{\bar{u}}^{-}, \hat{\bar{v}}^{-}, \hat{\bar{w}}^{-}\right)$, respectively. As the geometry is symmetrical by reflection against the $\mathrm{x}-\mathrm{y}$ plane, appropriate linear combinations of these traction and displacement vectors on top and bottom surfaces can be performed. Hence the 
part of the displacement field (involving $K_{1}^{S}, K_{2}^{S}, K_{3}^{S}$ ) that is symmetric under the reflection is decoupled from the remaining part (involving $K_{1}^{A}, K_{2}^{A}, K_{3}^{A}$ ) that is antisymmetric under the reflection. The $6 * 6$ matrix can be written into 2 smaller $3 * 3$ matrix equations, thus, reducing the calculation cost.

The symmetrical displacement solutions can be written as

$$
\hat{\bar{u}}_{s}=\frac{1}{2}\left(\begin{array}{cc}
\hat{\bar{u}}^{+} & -\hat{\bar{u}}^{-} \\
\hat{\bar{v}}^{+} & -\hat{\bar{v}}^{-} \\
\hat{\bar{w}}^{+} & +\hat{\bar{w}}^{-}
\end{array}\right)=\left[N^{S}\right] \cdot\left(\begin{array}{c}
K_{1}^{S} \\
K_{2}^{S} \\
K_{3}^{S}
\end{array}\right) .
$$

And the asymmetrical displacement solutions can be written as

$$
\hat{\bar{u}}^{A}=\frac{1}{2}\left(\begin{array}{cc}
\hat{\bar{u}}^{+} & +\hat{\bar{u}}^{-} \\
\hat{\bar{v}}^{+} & +\hat{\bar{v}}^{-} \\
\hat{\bar{w}}^{+} & -\hat{\bar{w}}^{-}
\end{array}\right)=\left[N^{A}\right] \cdot\left(\begin{array}{c}
K_{1}^{A} \\
K_{2}^{A} \\
K_{3}^{A}
\end{array}\right) .
$$

Considering the Hooke's law, the symmetrical stress solutions can be written as

$$
\hat{\bar{T}}^{S}=\frac{1}{2}\left(\begin{array}{cc}
\hat{\bar{T}}_{x z}^{+} & +\hat{\bar{T}}_{x z}^{-} \\
\hat{\bar{T}}_{y z}^{+} & +\hat{\bar{T}}_{y z}^{-} \\
\hat{\bar{T}}_{z z}^{+} & -\hat{\bar{T}}_{z z}^{-}
\end{array}\right)=\left[M^{S}\right] \cdot\left(\begin{array}{c}
K_{1}^{S} \\
K_{2}^{S} \\
K_{3}^{S}
\end{array}\right) .
$$

And the asymmetrical stress solution can be written as

$$
\hat{\bar{T}}^{A}=\frac{1}{2}\left(\begin{array}{cc}
\hat{\bar{T}}_{x z}^{+} & -\hat{\bar{T}}_{x z}^{-} \\
\hat{\bar{T}}_{y z}^{+} & -\hat{\bar{T}}_{y z}^{-} \\
\hat{\bar{T}}_{z z}^{+} & +\hat{\bar{T}}_{z z}^{-}
\end{array}\right)=\left[M^{A}\right] \cdot\left(\begin{array}{c}
K_{1}^{A} \\
K_{2}^{A} \\
K_{3}^{A}
\end{array}\right) .
$$

The tractions on the top and bottom surfaces can be calculated out with Eq. (2) or Eq. (3), which can be combined together to construct $\hat{\bar{T}}^{S}$ and $\hat{\bar{T}}^{A}$. Considering Eqs. (30) and (31), the six unknown coefficients $K_{1}^{S}, K_{2}^{S}, K_{3}^{S}$ and $K_{1}^{A}, K_{2}^{A}, K_{3}^{A}$ can be solved from the inverse of matrices $\left[M^{S}\right]$ and $\left[M^{A}\right]$. Then, the displacement components $\hat{\bar{u}}^{S}$ and $\hat{\bar{u}}^{A}$ can be solved from Eqs. (28) and (29). Given the Fourier coefficients, we can determine the displacement and stress fields at any point within the cubic film.

Now returning back to the total solution formula, it is described by the sum of the symmetrical and asymmetrical solutions. Finally, the total displacements and stress solutions of any point within the film can be written as

$$
\begin{gathered}
u_{j}^{i m g}=u_{j}^{S}+u_{j}^{A} ; \quad(j=1,2,3), \\
\sigma_{i j}^{i m g}=\sigma_{i j}^{S}+\sigma_{i j}^{A} ; \quad(i, j=1,2,3) .
\end{gathered}
$$

\section{Semi infinite crystal and crystal thin film with arbitrary orientation}

\section{General method}

In order to solve the same problem for arbitrarily oriented film, two sets of Cartesian coordinate should be employed, namely the original coordinate $(X, Y, Z)$, which is aligned with the basic crystal orientation, such as $\left[\begin{array}{lll}1 & 0 & 0\end{array}\right]$, $\left[\begin{array}{lll}0 & 1 & 0\end{array}\right]$, and $\left[\begin{array}{lll}0 & 0 & 1\end{array}\right]$ for bcc crystals, and the rotated coordinate $\left(X^{\prime}, Y^{\prime}, Z^{\prime}\right)$, which is aligned with the free surface orientation of semi-infinite space or thin film.

The rotation angles around the basic coordinate axis $(X, Y, Z)$ are $(\phi, \theta, \psi)$, respectively. Then the rotation matrix is

$$
T_{i j}=\left(\begin{array}{ccc}
\cos \theta \cos \psi & \cos \phi \sin \psi+\sin \phi \sin \theta \cos \psi & \sin \phi \sin \psi-\cos \phi \sin \theta \cos \psi \\
-\cos \theta \sin \psi & \cos \phi \cos \psi-\sin \phi \sin \theta \sin \psi & \sin \phi \cos \psi+\cos \phi \sin \theta \sin \psi \\
\sin \theta & -\sin \phi \cos \theta & \cos \phi \cos \theta
\end{array}\right) .
$$

The relation between positions $(x, y, z)$ in the original and positions $\left(x^{\prime}, y^{\prime}, z^{\prime}\right)$ in the rotated coordinates can be written as

$$
x_{i}^{\prime}=T_{i j} x_{j}
$$

The stiffness matrix in the rotated coordinate can be written as

$$
C_{i j k l}^{\prime}=T_{i g} T_{j h} C_{g h m n} T_{k m} T_{\mathrm{ln}} .
$$

In order to solve the image stress problem in the rotated coordinate, the following displacement field is assumed in the rotated coordinate:

$$
\begin{aligned}
\left(u^{\prime}, v^{\prime}, w^{\prime}\right)= & \sum_{k_{x^{\prime}}} \sum_{k_{y^{\prime}}}\left(U^{\prime}\left(k_{x^{\prime}}, k_{y^{\prime}}\right), V^{\prime}\left(k_{x^{\prime}}, k_{y^{\prime}}\right), W^{\prime}\left(k_{x^{\prime}}, k_{y^{\prime}}\right)\right) \\
& \times \exp \left(i k_{x^{\prime}} x^{\prime}+i k_{y^{\prime}} y^{\prime}+q^{\prime} z^{\prime}\right) .
\end{aligned}
$$

The resultant strain field in the rotated coordinate can be written as

$$
\varepsilon_{i j}^{\prime}=1 / 2\left(\partial u_{i}^{\prime} / \partial x_{j}^{\prime}+\partial u_{j}^{\prime} / \partial x_{i}^{\prime}\right) .
$$

Thus, the corresponding stress field can be calculated out through the Hooke's law in the rotated coordinate

$$
\sigma_{i j}^{\prime}=C_{i j k l}^{\prime} \varepsilon_{k l}^{\prime} .
$$

The equilibrium equation, stemming from the standing Christoffel equation, in the rotated coordinate can be written as 


$$
\sigma_{j i, j}^{\prime}=0
$$

After submitting the displacement field (37) into Eqs. (38)(40), the following sextic equation in $q^{\prime}$ can be produced

$$
\left\{D_{i j}^{\prime}\left(q^{\prime}\right)\right\}\left(\begin{array}{c}
U^{\prime} \\
V^{\prime} \\
W^{\prime}
\end{array}\right)=0 .
$$

In order that Eq. (41) will produce non-zero solution, the determinant of cofactor matrix of the equation must be zero

$$
\operatorname{det}\left|\left\{D_{i j}^{\prime}\left(q^{\prime}\right)\right\}\right|=0
$$

Considering the fact that the elastic deformation ability of a solid is necessary for crystal in arbitrary direction, the determinant of the cofactor matrix described by Eq. (42) will produce a sixth-order equation in $q^{\prime}$, which will produce three desired $q^{\prime}$ roots (with positive real parts). Note that there are real or complex roots, and the real part of the roots should be positive. These roots correspond to the attenuation properties of the displacements when getting far away from the free surface in the medium. For some special cases, the determinant can be written in the form of the product of two subdeterminants, namely the product of a second-order equation and a fourth-order equation, which will produce one independent root and the other two coupled roots. Then, the total displacement field is described by one independent displacement mode, and the coupled displacement modes in the sagittal plane perpendicular to the independent displacement mode.

After replacing the parameter $q^{\prime}$ in Eq. (37) with the calculated $q^{\prime}$ from Eq. (42), the final displacement field on the free surface of semi infinite space is

$$
\left(\begin{array}{c}
\hat{u}^{\prime} \\
\hat{v}^{\prime} \\
\hat{w}^{\prime}
\end{array}\right)=\left[N^{\prime}\right] \cdot\left(\begin{array}{c}
K_{1}^{\prime} \\
K_{2}^{\prime} \\
K_{3}^{\prime}
\end{array}\right)
$$

And the elastic relationship (39) will produce

$$
\left(\begin{array}{c}
\hat{\sigma}_{13}^{\prime} \\
\hat{\sigma}_{23}^{\prime} \\
\hat{\sigma}_{33}^{\prime}
\end{array}\right)=\left[M^{\prime}\right] \cdot\left(\begin{array}{c}
K_{1}^{\prime} \\
K_{2}^{\prime} \\
K_{3}^{\prime}
\end{array}\right)
$$

For a thin film with arbitrary oriented surfaces, a similar development can also be produced, by following the steps from Eqs. (34) to (42), but needs only to replace Eq. (37) with the following displacement field:

$$
\left\{\begin{aligned}
u^{\prime} & =\sum_{k_{x^{\prime}}} \sum_{k_{y^{\prime}}}\left[\left(U^{\prime}\right)^{S} \sinh \left(\left(q^{\prime}\right)^{S} \cdot z^{\prime}\right)+\left(U^{\prime}\right)^{A} \cosh \left(\left(q^{\prime}\right)^{A} \cdot z^{\prime}\right)\right] \cdot \exp \left(i k_{x^{\prime}} x^{\prime}+i k_{y^{\prime}} y^{\prime}\right), \\
v^{\prime} & =\sum_{k_{x^{\prime}}} \sum_{k_{y^{\prime}}}\left[\left(V^{\prime}\right)^{S} \sinh \left(\left(q^{\prime}\right)^{S} \cdot z^{\prime}\right)+\left(V^{\prime}\right)^{A} \cosh \left(\left(q^{\prime}\right)^{A} \cdot z^{\prime}\right)\right] \cdot \exp \left(i k_{x^{\prime}} x^{\prime}+i k_{y^{\prime}} y^{\prime}\right), \\
w^{\prime} & =\sum_{k_{x^{\prime}}} \sum_{k_{y^{\prime}}}\left[\left(W^{\prime}\right)^{S} \cosh \left(\left(q^{\prime}\right)^{S} \cdot z^{\prime}\right)+\left(W^{\prime}\right)^{A} \sinh \left(\left(q^{\prime}\right)^{A} \cdot z^{\prime}\right)\right] \cdot \exp \left(i k_{x^{\prime}} x^{\prime}+i k_{y^{\prime}} y^{\prime}\right) .
\end{aligned}\right.
$$

Considering that the equilibrium equations at the position $\pm z^{\prime}$ can be rewritten into 2 independent sets of equations on $\left(\left(U^{\prime}\right)^{S},\left(V^{\prime}\right)^{S},\left(W^{\prime}\right)^{S}\right)$ and $\left(\left(U^{\prime}\right)^{A},\left(V^{\prime}\right)^{A},\left(W^{\prime}\right)^{A}\right)$, the symmetrical and the asymmetrical parts, respectively. Then, three $\left(q_{j}^{\prime}\right)^{S}$ and three $\left(q_{j}^{\prime}\right)^{A}$ can be calculated out, respectively.

Finally, the symmetrical displacement solutions can be written as

$$
\left(\hat{\bar{u}}^{\prime}\right)^{S}=\frac{1}{2}\left(\begin{array}{cc}
\left(\hat{\bar{u}}^{\prime}\right)^{+} & -\left(\hat{\bar{u}}^{\prime}\right)^{-} \\
\left(\hat{\bar{v}}^{\prime}\right)^{+} & -\left(\hat{\bar{v}}^{\prime}\right)^{-} \\
\left(\hat{\bar{w}}^{\prime}\right)^{+} & +\left(\hat{\bar{w}}^{\prime}\right)^{-}
\end{array}\right)=\left[N^{\prime}\right]^{S} \cdot\left(\begin{array}{c}
K_{1}^{\prime} \\
K_{2}^{\prime} \\
K_{3}^{\prime}
\end{array}\right)^{S} .
$$

The asymmetrical displacement solutions can be written as

$$
\left(\hat{\bar{u}}^{\prime}\right)^{A}=\frac{1}{2}\left(\begin{array}{cc}
\left(\hat{\bar{u}}^{\prime}\right)^{+} & +\left(\hat{\bar{u}}^{\prime}\right)^{-} \\
\left(\hat{\bar{v}}^{\prime}\right)^{+} & +\left(\hat{\bar{v}}^{\prime}\right)^{-} \\
\left(\hat{\bar{w}}^{\prime}\right)^{+} & -\left(\hat{\bar{w}}^{\prime}\right)^{-}
\end{array}\right)=\left[N^{\prime}\right]^{A} \cdot\left(\begin{array}{c}
K_{1}^{\prime} \\
K_{2}^{\prime} \\
K_{3}^{\prime}
\end{array}\right)^{A}
$$

The symmetrical stress solutions can be written as

$$
\left(T^{\prime}\right)^{S}=\frac{1}{2}\left(\begin{array}{cc}
\left(\hat{T}_{x z}^{\prime}\right)^{+} & +\left(\hat{T}_{x z}^{\prime}\right)^{-} \\
\left(\hat{T}_{y z}^{\prime}\right)^{+} & +\left(\hat{T}_{y z}^{\prime}\right)^{-} \\
\left(\hat{T}_{z z}^{\prime}\right)^{+} & -\left(\hat{T}_{z z}^{\prime}\right)^{-}
\end{array}\right)=\left[\left(M^{\prime}\right)^{S}\right] \cdot\left(\begin{array}{c}
\left(K_{1}^{\prime}\right)^{S} \\
\left(K_{2}^{\prime}\right)^{S} \\
\left(K_{3}^{\prime}\right)^{S}
\end{array}\right)
$$

The asymmetrical stress solution can be written as

$$
\left(T^{\prime}\right)^{A}=\frac{1}{2}\left(\begin{array}{cc}
\left(\hat{T}_{x z}^{\prime}\right)^{+} & -\left(\hat{T}_{x z}^{\prime}\right)^{-} \\
\left(\hat{T}_{y z}^{\prime}\right)^{+} & -\left(\hat{T}_{y z}^{\prime}\right)^{-} \\
\left(\hat{T}_{z z}^{\prime}\right)^{+} & +\left(\hat{T}_{z z}^{\prime}\right)^{-}
\end{array}\right)=\left[\left(M^{\prime}\right)^{A}\right]\left(\begin{array}{c}
\left(K_{1}^{\prime}\right)^{A} \\
\left(K_{2}^{\prime}\right)^{A} \\
\left(K_{3}^{\prime}\right)^{A}
\end{array}\right) .
$$

Note that the corresponding displacement, strain, and stress field in the original coordinate can be converted into the rotated coordinate. Given the position of the film surface and of the dislocation segment of the loop in the rotated coordinate, the corresponding geometrical parameters can be converted into the original coordinate, and the stress field produced by dislocation loops or finite dislocation segments in the original coordinate can be calculated with formula (2) and (3), producing the traction stress field $\sigma_{l m}$ in the original coordinate, which can then be converted into the stress field $\sigma_{i j}^{\prime}$ in the rotated coordinates 


$$
\sigma_{i j}^{\prime}=T_{i l} T_{j m} \sigma_{l m}
$$

The stress field can be obtained from the displacement fields, and can also be written as

$$
\sigma\left(x^{\prime}, y^{\prime}, z^{\prime}\right)=\sum_{k_{x}} \sum_{k_{y}} \hat{\sigma}\left(k_{x^{\prime}}, k_{y^{\prime}}, z^{\prime}\right) \exp \left[i k_{x^{\prime}} x^{\prime}+i k_{y^{\prime}} y^{\prime}\right] .
$$

Then the corresponding coefficients vector $\left[K_{1}^{\prime}, K_{2}^{\prime}, K_{3}^{\prime}\right.$, ] for each Fourier mode in the rotated coordinate can be calculated out by matching each Fourier mode of the image stress at the free surface position described by Eq. (44), or alternately Eqs. (48) and (49) for then thin film, and Eq. (51).
The corresponding image displacement field, strain field, and stress field within the volume can then be calculated out. In the following, we present two examples of application of our theory for cubic crystals, one for the lower semi infinite space and one for the thin film.

\section{Lower semi infinite space with [1 1 -2], [-110], and [1 11 1] free surface orientation}

In order to show the reliability of this theory for arbitrary film orientation, the [1 $11-2],\left[\begin{array}{lll}-1 & 1 & 0\end{array}\right]$, and [ [ $\left.\begin{array}{lll}1 & 1 & 1\end{array}\right]$ coordinate is taken as an example. After producing the rotated stiffness matrix, the resultant transformed equilibrium equation in the rotated coordinate is

$$
\left\{\begin{array}{l}
{\left[C_{11}^{\prime} u_{x x}^{\prime}+C_{13}^{\prime} v_{y x}^{\prime}+C_{12}^{\prime} w_{z x}^{\prime}+C_{16}^{\prime}\left(u_{z x}^{\prime}+w_{x x}^{\prime}\right)\right]+\left[-C_{16}^{\prime}\left(v_{z y}^{\prime}+w_{y y}^{\prime}\right)+C_{55}^{\prime}\left(u_{y y}^{\prime}+v_{x y}^{\prime}\right)\right]+\left[C_{16}^{\prime} u_{x z}^{\prime}-C_{16}^{\prime} v_{y z}^{\prime}+C_{44}^{\prime}\left(u_{z z}^{\prime}+w_{x z}^{\prime}\right)\right]=0} \\
{\left[-C_{16}^{\prime}\left(v_{z x}^{\prime}+w_{y x}^{\prime}\right)+C_{55}^{\prime}\left(u_{y x}^{\prime}+v_{x x}^{\prime}\right)\right]+\left[C_{13}^{\prime} u_{x y}^{\prime}+C_{11}^{\prime} v_{y y}^{\prime}+C_{12}^{\prime} w_{z y}^{\prime}-C_{16}^{\prime}\left(u_{z y}^{\prime}+w_{x y}^{\prime}\right)\right]+\left[C_{44}^{\prime}\left(v_{z z}^{\prime}+w_{y z}^{\prime}\right)-C_{16}^{\prime}\left(u_{y z}^{\prime}+v_{x z}^{\prime}\right)\right]=0} \\
{\left[C_{16}^{\prime} u_{x x}^{\prime}-C_{16}^{\prime} v_{y x}^{\prime}+C_{44}^{\prime}\left(u_{z x}^{\prime}+w_{x x}^{\prime}\right)\right]+\left[C_{44}^{\prime}\left(v_{z y}^{\prime}+w_{y y}^{\prime}\right)-C_{16}^{\prime}\left(u_{y y}^{\prime}+v_{x y}^{\prime}\right)\right]+\left[C_{12}^{\prime} u_{x z}^{\prime}+C_{12}^{\prime} v_{y z}^{\prime}+C_{22}^{\prime} w_{z z}^{\prime}\right]=0 .}
\end{array}\right.
$$

In which,

$$
\begin{gathered}
H=2 C_{44}+C_{12}-C_{11} ; \quad C_{11}^{\prime}=C_{11}+\frac{1}{2} H ; \\
C_{12}^{\prime}=C_{12}-\frac{1}{3} H ; \quad C_{13}^{\prime}=C_{12}-\frac{1}{6} H . \\
C_{44}^{\prime}=C_{44}-\frac{1}{3} H ; \quad C_{55}^{\prime}=C_{44}-\frac{1}{6} H ; \\
C_{16}^{\prime}=\frac{\sqrt{2}}{6} H ; \quad C_{22}^{\prime}=C_{11}+\frac{2}{3} H .
\end{gathered}
$$

After following the steps from Eqs. (34) to (42), the following equilibrium equation in the rotated coordinate can be produced:

$$
\left(\begin{array}{lll}
D_{11}^{\prime} & D_{12}^{\prime} & D_{13}^{\prime} \\
D_{21}^{\prime} & D_{22}^{\prime} & D_{23}^{\prime} \\
D_{31}^{\prime} & D_{32}^{\prime} & D_{33}^{\prime}
\end{array}\right)\left(\begin{array}{c}
U^{\prime} \\
V^{\prime} \\
W^{\prime}
\end{array}\right)=0
$$

In which, the corresponding parameters are described in the Appendix D.

(1) The mode $\left(k_{x^{\prime}}=0, k_{y^{\prime}} \neq 0\right)$ and $\left(k_{x^{\prime}}=0, k_{y^{\prime}} \neq 0\right)$

In order to produce corresponding non-zero roots, the determinant should be zero. The determinant of the cofactor matrix in Eq. (53) will produce sextic equation producing 6 roots in $q^{\prime}$, but only 3 complex roots with positive real part are employed for producing the displacement field. After producing the attenuation coefficient, the corresponding displacement field can be written as

$$
\frac{U_{J}^{\prime}}{\xi_{j}^{\prime}}=\frac{V_{J}^{\prime}}{\eta_{j}^{\prime}}=\frac{W_{J}^{\prime}}{\zeta_{j}^{\prime}}=K_{j}^{\prime} ; \quad(j=1,2,3) .
$$

In which, the corresponding $\left(\xi_{j}^{\prime}, \eta_{j}^{\prime}, \zeta_{j}^{\prime}\right)$ are the elements of along the first row of the cofactor expansion matrix of Eq. (53) cofactor matrix.
(2) When $\left(k_{x^{\prime}} \neq 0, k_{y^{\prime}}=0\right)$

The determinant will be reduced into the product of two sub-determinant, which will produce three desired roots: This equation set has three roots: $q_{1}^{\prime}=\left(i k_{x^{\prime}} C_{16}^{\prime}+\left|k_{x^{\prime}}\right|\right.$. $\left.\sqrt{\left(C_{55}^{\prime} C_{44}^{\prime}-C_{16}^{\prime} C_{16}^{\prime}\right)}\right) / C_{44}^{\prime}$, and $\left(q_{2}^{\prime}, q_{3}^{\prime}\right)$ are the roots, with positive real parts, of the following equation:

$$
\begin{aligned}
& \left(q_{j}^{\prime}\right)^{4} \cdot C_{44}^{\prime} C_{22}^{\prime}+\left(q_{j}^{\prime}\right)^{3} \cdot 2 i k_{x^{\prime}} C_{16}^{\prime} C_{22}^{\prime}+\left(q_{j}^{\prime}\right)^{2} \cdot k_{x^{\prime}}^{2} \\
& \quad \times\left(2 C_{44}^{\prime} C_{12}^{\prime}+C_{12}^{\prime} C_{12}^{\prime}-C_{11}^{\prime} C_{22}^{\prime}\right)+q_{j}^{\prime} \cdot 2 i k_{x^{\prime}}^{3} \cdot C_{12}^{\prime} C_{16}^{\prime} \\
& \quad+k_{x^{\prime}}^{4} \cdot\left(C_{11}^{\prime} C_{44}^{\prime}-C_{16}^{\prime} C_{16}^{\prime}\right)=0 ; \quad(j=2,3) .
\end{aligned}
$$

Then the displacement field on the free surface in Fourier space is

$$
\left(\begin{array}{c}
\hat{\bar{u}}^{\prime} \\
\hat{\bar{v}}^{\prime} \\
\hat{\bar{w}}^{\prime}
\end{array}\right)=\left[N^{\prime}\right] \cdot\left(\begin{array}{c}
K_{1}^{\prime} \\
K_{2}^{\prime} \\
K_{3}^{\prime}
\end{array}\right)
$$

The corresponding traction stress components $\left(\sigma_{x z}^{\prime}, \sigma_{y z}^{\prime}, \sigma_{z z}^{\prime}\right)$ on the surface $z^{\prime}=0$ are composed of the coefficients $K_{1}^{\prime}, K_{2}^{\prime}, K_{3}^{\prime}$ through the matrix equation

$$
\left(\begin{array}{c}
\hat{T}_{x z}^{\prime} \\
\hat{T}_{y z}^{\prime} \\
\hat{T}_{z z}^{\prime}
\end{array}\right)=\left[M^{\prime}\right] \cdot\left(\begin{array}{c}
K_{1}^{\prime} \\
K_{2}^{\prime} \\
K_{3}^{\prime}
\end{array}\right)
$$

\section{Cubic film with [1 $1-2],\left[\begin{array}{ll}-1 & 10\end{array}\right]$, and [ 1111$]$ free surface orientation}

Considering the displacement field (45), and follow the steps from Eqs. (46)-(49) for the symmetrical and 
asymmetrical parts, respectively. After finishing the steps from Eqs. (34) to (42), the equilibrium equations can be written in the rotated coordinate. Considering the independent properties $\left(\left(U^{\prime}\right)^{S},\left(V^{\prime}\right)^{S},\left(W^{\prime}\right)^{S}\right)$ and $\left(\left(U^{\prime}\right)^{A},\left(V^{\prime}\right)^{A},\left(W^{\prime}\right)^{A}\right)$, the equilibrium equation can be written separately as the symmetrical and asymmetrical parts.

The symmetrical part which can be written as

$$
\left(\begin{array}{ccc}
\left(D_{11}^{\prime}\right)^{S} & \left(D_{12}^{\prime}\right)^{S} & \left(D_{13}^{\prime}\right)^{S} \\
\left(D_{21}^{\prime}\right)^{S} & \left(D_{22}^{\prime}\right)^{S} & \left(D_{22}^{\prime}\right)^{S} \\
\left(D_{31}^{\prime}\right)^{S} & \left(D_{32}^{\prime}\right)^{S} & \left(D_{33}^{\prime}\right)^{S}
\end{array}\right)\left(\begin{array}{c}
\left(U^{\prime}\right)^{S} \\
\left(V^{\prime}\right)^{S} \\
\left(W^{\prime}\right)^{S}
\end{array}\right)=0 .
$$

The corresponding parameters are described in Appendix E. In order to produce the corresponding non-zero roots, the determinant should be zero. The determinant of the cofactor matrix in Eq. (58) will produce sextic equation producing 6 roots in $\left(q^{\prime}\right)^{S}$, but only 3 complex roots with positive real part are selected for deciding the displacement. After doing the cofactor expansion along the first row, the corresponding $\left(\left(\xi_{j}^{\prime}\right)^{S},\left(\eta_{j}^{\prime}\right)^{S},\left(\zeta_{j}^{\prime}\right)^{S}\right)$ are the elements of along the first row of the cofactor expansion matrix in Eq. (58).

The asymmetrical parts which can be written as

$$
\left(\begin{array}{ccc}
\left(D_{11}^{\prime}\right)^{A} & \left(D_{12}^{\prime}\right)^{A} & \left(D_{13}^{\prime}\right)^{A} \\
\left(D_{21}^{\prime}\right)^{A} & \left(D_{22}^{\prime}\right)^{A} & \left(D_{23}^{\prime}\right)^{A} \\
\left(D_{31}^{\prime}\right)^{A} & \left(D_{32}^{\prime}\right)^{A} & \left(D_{33}^{\prime}\right)^{A}
\end{array}\right)\left(\begin{array}{c}
\left(U^{\prime}\right)^{A} \\
\left(V^{\prime}\right)^{A} \\
\left(W^{\prime}\right)^{A}
\end{array}\right)=0 .
$$

Again, the corresponding parameters are described in Appendix E. In order to produce corresponding non-zero roots, the determinant should be zero. The determinant of the cofactor matrix In Eq. (59) will produce sextic equation producing 6 roots in $\left(q^{\prime}\right)^{A}$, but only 3 complex roots with positive real part are selected for deciding the displacement. After doing the cofactor expansion along the first row, the corresponding $\left(\left(\xi_{j}^{\prime}\right)^{A},\left(\eta_{j}^{\prime}\right)^{A},\left(\zeta_{j}^{\prime}\right)^{A}\right)$ are the elements of along the first row of the cofactor expansion matrix in Eq. (59).

(1) The modes $\left(k_{x^{\prime}}=0, k_{y^{\prime}} \neq 0\right)$ and $\left(k_{x^{\prime}}=0, k_{y^{\prime}} \neq 0\right)$

The corresponding displacement field can be written as

$$
\frac{\left(U_{j}^{\prime}\right)^{S}}{\left(\xi_{j}^{\prime}\right)^{S}}=\frac{\left(V_{j}^{\prime}\right)^{S}}{\left(\eta_{j}^{\prime}\right)^{S}}=\frac{\left(W_{j}^{\prime}\right)^{S}}{\left(\zeta_{j}^{\prime}\right)^{S}}=\left(K_{j}^{\prime}\right)^{S} ; \quad(j=1,2,3) .
$$

The corresponding displacement field can be written as

$$
\frac{\left(U_{j}^{\prime}\right)^{A}}{\left(\xi_{j}^{\prime}\right)^{A}}=\frac{\left(V_{j}^{\prime}\right)^{A}}{\left(\eta_{j}^{\prime}\right)^{A}}=\frac{\left(W_{j}^{\prime}\right)^{A}}{\left(\zeta_{j}^{\prime}\right)^{A}}=\left(K_{j}^{\prime}\right)^{A} ; \quad(j=1,2,3) .
$$

(2) When $\left(k_{x^{\prime}} \neq 0, k_{y^{\prime}}=0\right)$

As to the symmetrical part, the determinant will be reduced into the product of two sub-determinant, which will produce three desired roots: $\left(q_{1}^{\prime}\right)^{S}=\left(i k_{x^{\prime}} C_{16}^{\prime}+\left|k_{x^{\prime}}\right|\right.$. $\left.\sqrt{\left(C_{55}^{\prime} C_{44}^{\prime}-C_{16}^{\prime} C_{16}^{\prime}\right)}\right) / C_{44}^{\prime}$, and $\left(\left(q_{2}^{\prime}\right)^{S},\left(q_{3}^{\prime}\right)^{S}\right)$ are the roots (with positive real parts) of the following equation:

$$
\begin{aligned}
& \left(\left(q_{j}^{\prime}\right)^{S}\right)^{4} \cdot C_{44}^{\prime} C_{22}^{\prime}+\left(\left(q_{j}^{\prime}\right)^{S}\right)^{3} \cdot 2 i k_{x^{\prime}} C_{16}^{\prime} C_{22}^{\prime} \\
& \quad+\left(\left(q_{j}^{\prime}\right)^{S}\right)^{2} \cdot k_{x^{\prime}}^{2} \cdot\left(2 C_{44}^{\prime} C_{12}^{\prime}+C_{12}^{\prime} C_{12}^{\prime}-C_{11}^{\prime} C_{22}^{\prime}\right) \\
& \quad+\left(q_{j}^{\prime}\right)^{S} \cdot 2 i k_{x^{\prime}}^{3} \cdot C_{12}^{\prime} C_{16}^{\prime}+k_{x^{\prime}}^{4} \cdot\left(C_{11}^{\prime} C_{44}^{\prime}-C_{16}^{\prime} C_{16}^{\prime}\right)=0 \\
& \quad(j=2,3) .
\end{aligned}
$$

As to the asymmetrical part, the determinant will be reduced into the product of two sub-determinants, which will produce three desired roots: $\left(q_{1}^{\prime}\right)^{A}=\left(i k_{x^{\prime}} C_{16}^{\prime}+\left|k_{x^{\prime}}\right|\right.$. $\left.\sqrt{\left(C_{55}^{\prime} C_{44}^{\prime}-C_{16}^{\prime} C_{16}^{\prime}\right)}\right) / C_{44}^{\prime}$, and $\left(\left(q_{2}^{\prime}\right)^{A},\left(q_{3}^{\prime}\right)^{A}\right)$ are the roots (with positive real parts) of the following equation:

$$
\begin{aligned}
& \left(\left(q_{j}^{\prime}\right)^{A}\right)^{4} \cdot C_{44}^{\prime} C_{22}^{\prime}+\left(\left(q_{j}^{\prime}\right)^{A}\right)^{3} \cdot 2 i k_{x^{\prime}} C_{16}^{\prime} C_{22}^{\prime} \\
& \quad+\left(\left(q_{j}^{\prime}\right)^{A}\right)^{2} \cdot k_{x^{\prime}}^{2} \cdot\left(2 C_{44}^{\prime} C_{12}^{\prime}+C_{12}^{\prime} C_{12}^{\prime}-C_{11}^{\prime} C_{22}^{\prime}\right) \\
& \quad+\left(q_{j}^{\prime}\right)^{A} \cdot 2 i k_{x^{\prime}}^{3} \cdot C_{12}^{\prime} C_{16}^{\prime}+k_{x^{\prime}}^{4} \cdot\left(C_{11}^{\prime} C_{44}^{\prime}-C_{16}^{\prime} C_{16}^{\prime}\right)=0 \\
& \quad(j=2,3) .
\end{aligned}
$$

Considering the displacement field that

$$
\begin{gathered}
\left(\hat{u}^{\prime}\right)^{S}=\frac{1}{2}\left[\begin{array}{c}
\left(\left(u^{\prime}\right)^{+}-\left(u^{\prime}\right)^{-}\right) \\
\left(\left(v^{\prime}\right)^{+}-\left(v^{\prime}\right)^{-}\right) \\
\left(\left(w^{\prime}\right)^{+}+\left(w^{\prime}\right)^{-}\right)
\end{array}\right]=\left[\left(N^{\prime}\right)^{S}\right] \cdot\left(\begin{array}{c}
\left(K_{1}^{\prime}\right)^{S} \\
\left(K_{2}^{\prime}\right)^{S} \\
\left(K_{3}^{\prime}\right)^{S}
\end{array}\right),(66) \\
\left(\hat{u}^{\prime}\right)^{A}=\frac{1}{2}\left[\begin{array}{c}
\left(\left(u^{\prime}\right)^{+}+\left(u^{\prime}\right)^{-}\right) \\
\left(\left(v^{\prime}\right)^{+}+\left(v^{\prime}\right)^{-}\right) \\
\left(\left(w^{\prime}\right)^{+}-\left(w^{\prime}\right)^{-}\right)
\end{array}\right]=\left[\left(N^{\prime}\right)^{A}\right] \cdot\left(\begin{array}{c}
\left(K_{1}^{\prime}\right)^{A} \\
\left(K_{2}^{\prime}\right)^{A} \\
\left(K_{3}^{\prime}\right)^{A}
\end{array}\right) .
\end{gathered}
$$

The stress field is

$$
\begin{aligned}
& {\left[\begin{array}{c}
\left(\hat{\sigma}_{x z}^{\prime}\right)^{S} \\
\left(\hat{\sigma}_{y z}^{\prime}\right)^{S} \\
\left(\hat{\sigma}_{z z}^{\prime}\right)^{S}
\end{array}\right]=\left[\left(M^{\prime}\right)^{S}\right] \cdot\left(\begin{array}{c}
\left(K_{1}^{\prime}\right)^{S} \\
\left(K_{2}^{\prime}\right)^{S} \\
\left(K_{3}^{\prime}\right)^{S}
\end{array}\right),} \\
& {\left[\begin{array}{c}
\left(\hat{\sigma}_{x z}^{\prime}\right)^{A} \\
\left(\hat{\sigma}_{y z}^{\prime}\right)^{A} \\
\left(\hat{\sigma}_{z z}^{\prime}\right)^{A}
\end{array}\right]=\left[\left(M^{\prime}\right)^{A}\right] \cdot\left(\begin{array}{l}
\left(K_{1}^{\prime}\right)^{A} \\
\left(K_{2}^{\prime}\right)^{A} \\
\left(K_{3}^{\prime}\right)^{A}
\end{array}\right) .}
\end{aligned}
$$

\section{Calculation of the image energy of the thin film}

Let $\hat{T}^{-}$and $\hat{u}^{-}$be the traction force and displacement field on the surface of the lower semi infinite space for each Fourier mode. They are related to each other through $\left[\mathrm{M}^{-}\right]$ and $\left[N^{-}\right]$matrix

$$
\hat{T}^{-}=\left[M^{-}\right]\left[N^{-}\right]^{-1} \hat{u}^{-} .
$$

Let $\hat{T}^{+}$and $\hat{u}^{+}$be the traction force and displacement field on the surface of the upper semi infinite space for each 
Fourier mode. They are related to each other through $\left[\mathrm{M}^{+}\right]$ and $\left[N^{+}\right]$matrix

$$
\hat{T}^{+}=-\left[M^{+}\right]\left[N^{+}\right]^{-1} \hat{u}^{+} .
$$

The traction forces on the lower and upper semi infinite spaces should cancel each other, thus, producing

$$
\hat{f}=\hat{T}^{-}+\hat{T}^{+}=0 .
$$

The surface displacement induced by the image stress on the surfaces of the two semi infinite spaces will not match. The equivalent problem for the infinite medium will have a displacement jump, which can be written for each Fourier mode

$$
[\hat{u}]=\hat{u}^{-}-\hat{u}^{+}=\left(\left[N^{-}\right]\left[M^{-}\right]^{-1}-\left[N^{+}\right]\left[M^{+}\right]^{-1}\right) \hat{T}^{-} .
$$

Then the displacement jump $u(x, y)$ in Cartesian coordinate can be produced from Eq. (71), and the image energy is the difference between the total energy and infinite energy

$$
E^{i m g}=-\frac{1}{2} \int_{-L_{x} / 2}^{L_{x} / 2} \int_{-L_{y} / 2}^{L_{y} / 2} T(x, y) \cdot u(x, y) \cdot d x d y .
$$

The energy relationship is

$$
E^{\text {total }}=E^{\infty}+E^{\text {image }} .
$$

For the film, the image energy should consider both the upper surface and the lower surface, consists of 4 contributing parts, following the steps from Eqs. (68) to (72), thus, producing the image energy formula:

$$
\begin{aligned}
E^{i m g}= & -\frac{1}{2} \int_{-L_{x} / 2}^{L_{x} / 2} \int_{-L_{y} / 2}^{L_{y} / 2}\left(T^{+}(x, y) \cdot u^{+}(x, y)\right. \\
& \left.+T^{-}(x, y) \cdot u^{-}(x, y)\right) \cdot d x d y .
\end{aligned}
$$

In which, $u^{+}(x, y)$ and $u^{-}(x, y)$ are the displacement jump on the upper and lower surfaces, respectively.

\section{CALCULATION EXAMPLE}

\section{A. The relative error dependence on wave number and mesh density}

The calculation method is optimized with respect to the wave number in Fourier space. The image displacement and image energy relative errors as a function of the wave number are first calculated. The case of a nanometric [001](001) loop and a nanometric 1/2[111](111) loop in bcc Fe are considered for studying the wave number vs relative error, respectively. our types of modes in semi infinite space and thin film are considered: Voigt isotropic equivalent bcc $\mathrm{Fe}$, the crystallographic orientations of $(x, y, z)$ coordinates on the free surface are [100], [010], and [001], respectively; anisotropic bcc Fe, the crystallographic orientations of $(x, y, z)$ coordinates on the free surface are [100], [010], and [001], respectively; anisotropic bcc Fe, the crystallographic orientations of $\left(x^{\prime}, y^{\prime}, z^{\prime}\right)$ coordinates on the free surface are: [112]], [1110], and [111],
TABLE I. Elastic parameters of Fe used for the calculations.

\begin{tabular}{lccc}
\hline \hline Source & $\begin{array}{c}\text { Anisotropic } \\
\text { elastic } \\
\text { parameters }\end{array}$ & $\begin{array}{c}\text { Voigt } \\
\text { isotropic } \\
\text { modulus }\end{array}$ & $\begin{array}{c}\text { Crystallographic } \\
\text { parameters }\end{array}$ \\
\hline $\mathrm{Fe}^{27}$ & $C_{11}=232.2 \mathrm{GPa}$ & $\mu=89.52 \mathrm{GPa}$ & $a=0.28665 \mathrm{~nm}$ \\
& $C_{12}=135.6 \mathrm{GPa}$ & $\nu=0.2735$ & $b=0.28665 \mathrm{~nm}$ \\
& $C_{44}=117 \mathrm{GPa}$ & & $c=0.28665 \mathrm{~nm}$ \\
\hline \hline
\end{tabular}

respectively. The anisotropic and Voigt equivalent elastic modulus parameters of $\mathrm{Fe}$ at room temperature used for the calculation are listed in Table I.

Fig. 2(a) shows the relative error of the surface image displacement amplitude, $\Delta d=\left|\max \left(u_{z}\right)-\min \left(u_{z}\right)\right|$, induced by the same dislocation loop in a semi infinite crystal for Voigt, using isotropy, while Fig. 2(b) shows the relative error of image energy $E^{i m g}$. For the semi infinite space case, the radius of the loop is $3 \mathrm{~nm}$, and the depth of loop center under the free surface is $14 \mathrm{~nm}$, the periodic length is $160 \mathrm{~nm}$ along the free surface coordinates. Figs. 2(c) and 2(d) show the relative error of the image displacement amplitude, $\Delta d=\left|\max \left(u_{z}\right)-\min \left(u_{z}\right)\right|$, and the relative error of the image energy $E^{i m g}$ on the upper and lower free surfaces induced by the same dislocation loop in the middle of the film. For the thin film case, the radius of the dislocation loop is also $3 \mathrm{~nm}$ and the depth of the dislocation loop center under the top free surface is also $14 \mathrm{~nm}$. The film thickness is $28 \mathrm{~nm}$, implying that the loop is in the centre of the foil, and the periodic length is $180 \mathrm{~nm}$ along the free surface coordinates.

All the relative error results show exponential convergence as the wave number $k_{x}=k_{y}$ (or $k_{x^{\prime}}=k_{y^{\prime}}$ ) is increased. It can be seen that the slopes of the displacement or image energy relative error curves of the thin film cases are smaller than the slopes of semi infinite space cases for both isotropic and anisotropic theories, indicating slower convergence in the thin film. The relative error curves of the image displacement and image energy converge slower in rotated surface crystal coordinate than in the basic crystal surface coordinate in both semi infinite space and thin film cases. The slopes of image energy error are generally higher than that from the displacement for both semi infinite space and thin film, which means that the image energy calculation converges faster than the displacement convergence rate, when the wave number increases.

\section{B. Surface deformation of an anisotropic crystal thin film containing a dislocation loop}

In this subsection, the image stress induced displacement fields are calculated to demonstrate the difference between Voigt equivalent isotropic method and anisotropic method for bcc Fe single crystal. ${ }^{27}$

Fig. 3 shows the image stress induced in-plane and outof-plane displacement fields of $1 / 2[111](111)$ loop on the free surfaces of [111] oriented bcc Fe single crystal thin film, the crystallographic orientations of $\left(x^{\prime}, y^{\prime}, z^{\prime}\right)$ coordinates are: $[11 \overline{2}],[\overline{1} 10]$, and [111], respectively. Figs. 3(a)-3(c) are the $\left(u^{\prime}, v^{\prime}, w^{\prime}\right)$ from Voigt isotropic elasticity on the upper surface. Figs. 3(d)-3(f) are the $\left(u^{\prime}, v^{\prime}, w^{\prime}\right)$ from Voigt isotropic 

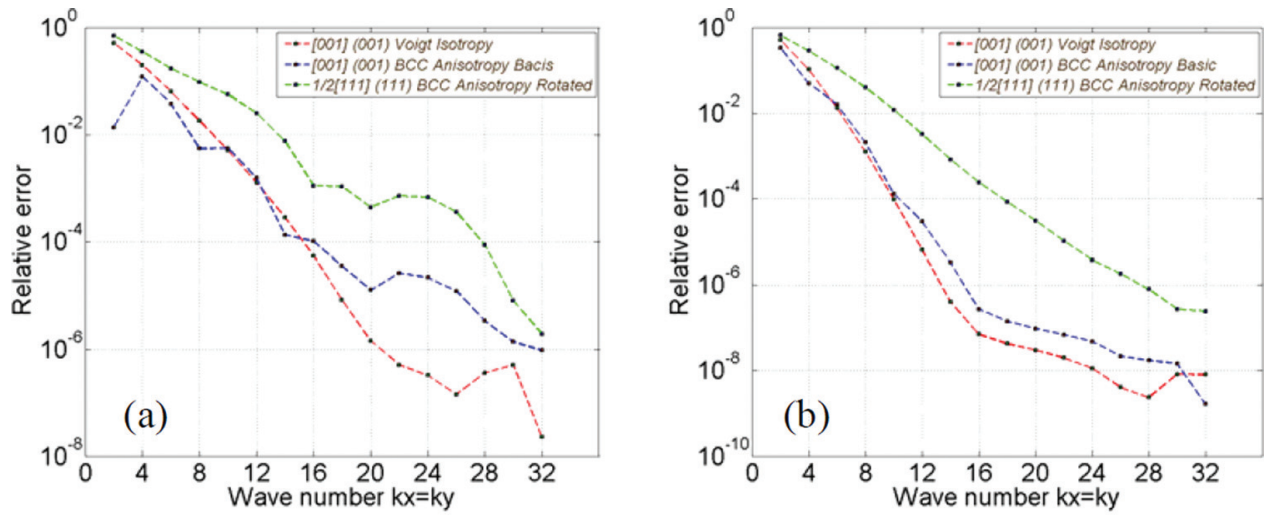

FIG. 2. Relative errors of calculation using anisotropic elasticity of the image displacement and image energy of pure bcc Fe containing a nanometric dislocation loop. Relative error of (a) the image displacement, and (b) the image energy
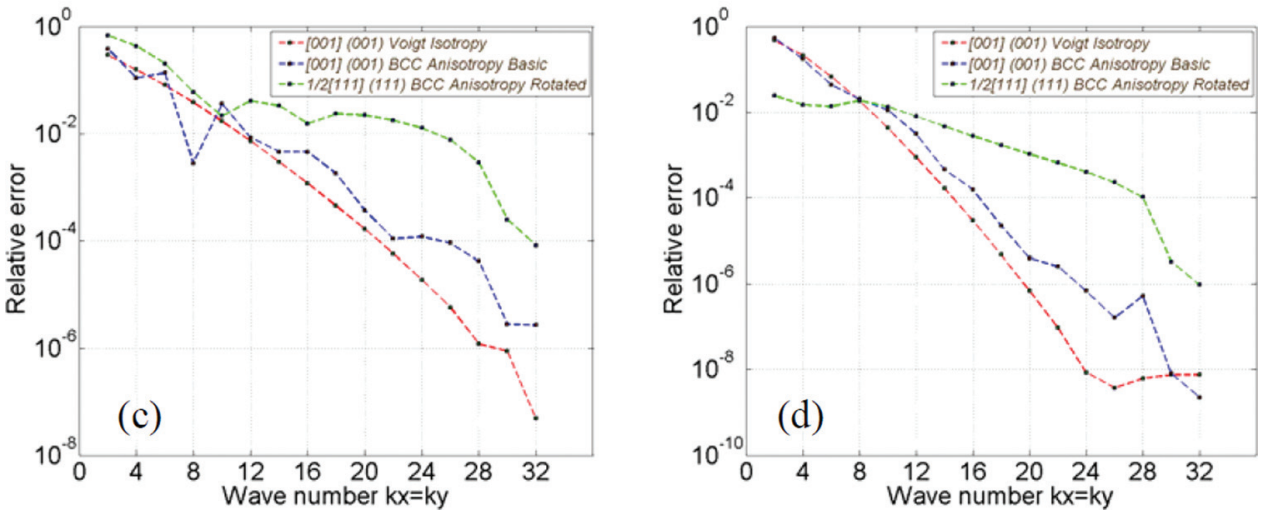
on the free surface of a semi infinite space. Relative error of (c) the image displacement, and (d) the image energy on the free surface of a thin film.

elasticity on the lower surface. Figs. 3(g)-3(i) are the $\left(u^{\prime}, v^{\prime}, w^{\prime}\right)$ from anisotropic elasticity on the upper surface. Figs. 3(j)-3(1) are the $\left(u^{\prime}, v^{\prime}, w^{\prime}\right)$ from anisotropic elasticity on the lower surface. The calculation parameters for bcc Fe single crystal are: $L_{x^{\prime}}=L_{y^{\prime}}=180 \mathrm{~nm}, k_{x^{\prime}}=k_{y^{\prime}}=30$, radius $=3 \mathrm{~nm}$, depth $=14 \mathrm{~nm}$, thickness $=28 \mathrm{~nm}$.
From the calculation results shown in Fig. 3, one can conclude that: when the crystallographic orientations of $\left(x^{\prime}, y^{\prime}, z^{\prime}\right)$ coordinates are: $[11 \overline{2}],[\overline{1} 10]$, and $[111]$, respectively, a stronger image stress induced in-plane and out of plane displacement amplitude is produced with the anisotropic elasticity for $1 / 2[111](111)$ loop in bcc Fe, relative to the amplitude calculated by Voigt isotropic methods. For the defect configuration

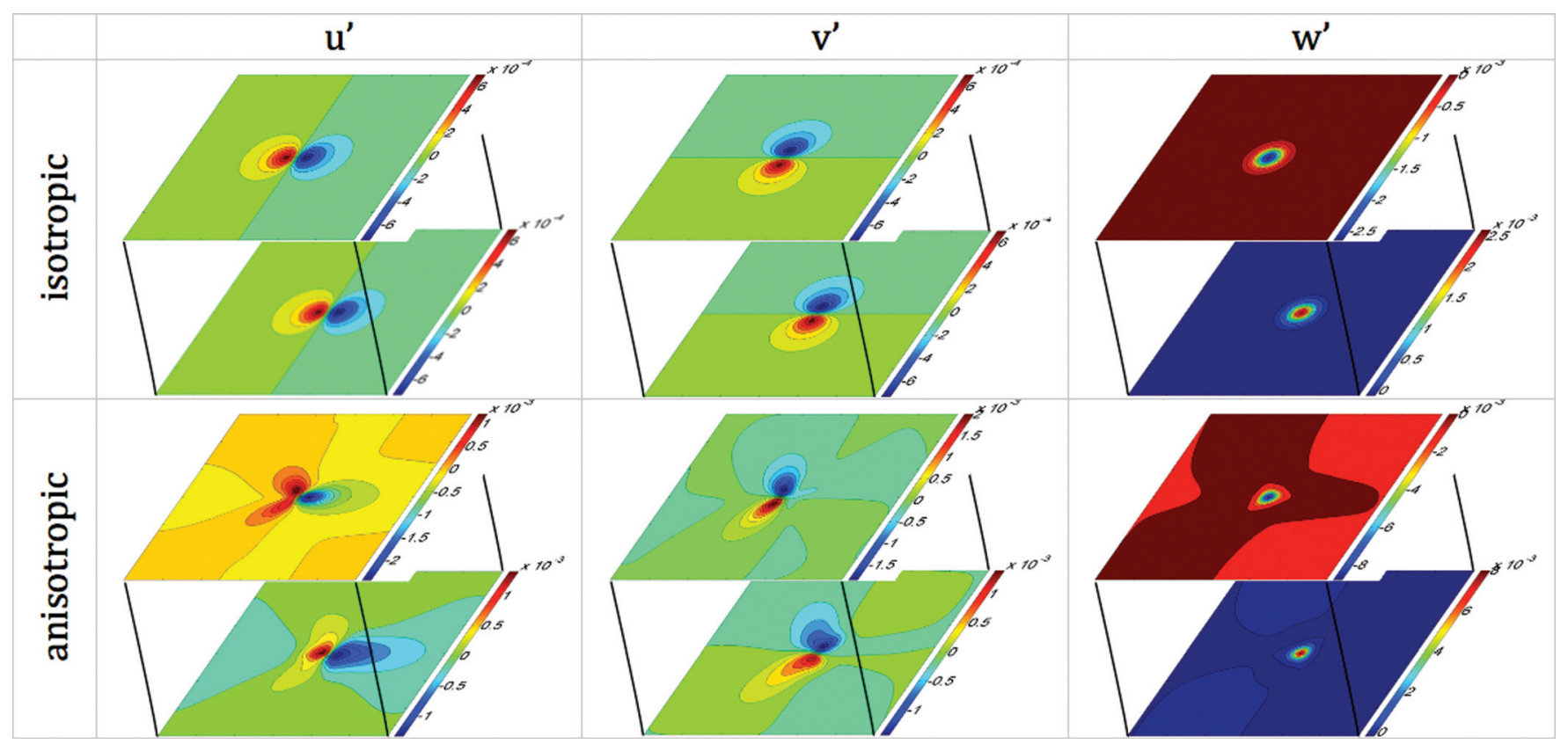

FIG. 3. Image stress induced in-plane and out-of-plane displacement fields $\left(\mathrm{u}^{\prime}, \mathrm{v}^{\prime}, \mathrm{w}^{\prime}\right)$ by a 1/2[111](111) loop on the free top and bottom surfaces of a [111] oriented bcc Fe single crystal thin film calculated using isotropic elasticity from Voigt and anisotropic elasticity. $L_{x^{\prime}}=L_{y^{\prime}}=180 \mathrm{~nm}, k_{x^{\prime}}=k_{y^{\prime}}=30$, radius $=3 \mathrm{~nm}$, depth $=14 \mathrm{~nm}$, thickness $=28 \mathrm{~nm}$. 
considered in this paper, with a $3 \mathrm{~nm}$ loop that is $14 \mathrm{~nm}$ deep, it amounts to a surface dimple amplitude $\Delta d=\mid \max \left(u_{z}\right)-$ $\min \left(u_{z}\right) \mid$ that is $0.0091 \mathrm{~nm}$ for the upper surface and $0.0089 \mathrm{~nm}$ for the lower surface in the anisotropic calculation, compared to $0.0027 \mathrm{~nm}$ for the upper surface and $0.0027 \mathrm{~nm}$ for the lower surface in the isotropic case. It shows that anisotropy cannot be neglected when calculating the image stress induced 3D displacement fields of free surfaces.

\section{CONCLUSION}

A method to calculate the image stress for defects in anisotropic semi infinite crystal and crystal thin film with arbitrary crystal orientation has been developed. Besides studying dislocations, this theory can also be used for analyzing the surface effects of other types of defects, such as irradiation induced He bubbles, precipitates, etc. The method was applied to pure bcc Fe single crystals for calculating the image stress effect due to a dislocation loop close to the free surface in semi infinite space and thin film. The image stress effect of dislocation loop depends on not only the film thick- ness but also its relative crystallographic orientation, the loop's Burgers vectors, habit plane, and location in the film. The calculation results show that a stronger image stress induced in-plane and out-of plane displacement difference is produced with the anisotropic elasticity for bcc Fe, relative to the isotropic case, calculated by either Voigt or Reuss methods, thus, proving that the anisotropic ratio has a strong influence on the image stress induced 3D displacement fields.

\section{ACKNOWLEDGMENTS}

Work was performed within the Swiss Generation IV Program and EFDA. It was partially financed by EU-projects MATTER.

\section{APPENDIX A: $M$ AND $N$ MATRIXES IN LOWER SEMI INFINITE SPACE}

(a) The $\left(k_{x} \neq 0, k_{y} \neq 0\right)$ mode

$$
\begin{gathered}
\left\{\begin{array}{l}
\xi_{j}=\left(-k_{y}^{2} C_{11}-k_{x}^{2} C_{44}+q_{j}^{2} C_{44}\right)\left(q_{j}^{2} C_{11}-k_{x}^{2} C_{44}-k_{y}^{2} C_{44}\right)+k_{y}^{2} q_{j}^{2}\left(C_{12}+C_{44}\right)^{2} \\
\eta_{j}=-k_{x} k_{y} q_{j}^{2}\left(C_{12}+C_{44}\right)^{2}+k_{x} k_{y}\left(C_{12}+C_{44}\right)\left(q_{j}^{2} C_{11}-k_{x}^{2} C_{44}-k_{y}^{2} C_{44}\right) ; \quad(j=1,2,3) \\
\zeta_{j}=-i k_{x} k_{y}^{2} q_{j}\left(C_{12}+C_{44}\right)^{2}-i k_{x} q_{j}\left(C_{12}+C_{44}\right)\left(-k_{y}^{2} C_{11}-k_{x}^{2} C_{44}+q_{j}^{2} C_{44}\right) ;
\end{array}\right. \\
{\left[N^{-}\right]=\left(\begin{array}{lll}
N_{11} & N_{12} & N_{13} \\
N_{21} & N_{22} & N_{23} \\
N_{31} & N_{32} & N_{33}
\end{array}\right) ; \quad\left\{\begin{array}{l}
N_{1 j}=\xi_{j} e^{+q_{j} z} ; \\
N_{2 j}=\eta_{j} e^{+q_{j} z} ; \quad(j=1,2,3) \\
N_{3 j}=\zeta_{j} e^{+q_{j} z} ;
\end{array} \quad(j=1,2,3)\right.} \\
{\left[M^{-}\right]=\left(\begin{array}{lll}
M_{11} & M_{12} & M_{13} \\
M_{21} & M_{22} & M_{23} \\
M_{31} & M_{32} & M_{33}
\end{array}\right) ; \quad\left\{\begin{array}{l}
M_{1 j}=C_{44}\left(\xi_{j} q_{j}+i k_{x} \zeta_{j}\right) e^{+q_{j} z} ; \\
M_{2 j}=C_{44}\left(\eta_{j} q_{j}+i k_{y} \zeta_{j}\right) e^{+q_{j} z} ; \\
M_{3 j}=\left(i k_{x} C_{12} \xi_{j}+i k_{y} C_{12} \eta_{j}+C_{11} \zeta_{j} q_{j}\right) e^{+q_{j} z} ;
\end{array}\right.}
\end{gathered}
$$

(b) The $\left(k_{x}=0, k_{y} \neq 0\right)$ mode

$$
\begin{gathered}
{\left[N^{-}\right]=\left(\begin{array}{ccc}
N_{11} & 0 & 0 \\
0 & N_{22} & N_{23} \\
0 & N_{32} & N_{33}
\end{array}\right) ; \quad\left\{\begin{array}{l}
N_{11}=e^{+\left|k_{y}\right| z} ; \\
N_{2 j}=i k_{y} q_{j}\left(C_{12}+C_{44}\right) e^{+q_{j} z} ; \quad(j=2,3) \\
N_{3 j}=-\left(C_{44} q_{j}^{2}-C_{11} k_{y}^{2}\right) e^{+q_{j} z} ;
\end{array}\right.} \\
{\left[M^{-}\right]=\left(\begin{array}{ccc}
M_{11} & 0 & 0 \\
0 & M_{22} & M_{23} \\
0 & M_{32} & M_{33}
\end{array}\right) ; \quad\left\{\begin{array}{l}
M_{11}=\left|k_{y}\right| C_{44} e^{+\left|k_{y}\right| z} ; \\
M_{2 j}=i C_{44}\left(C_{12}+C_{44}\right) k_{y} q_{j}^{2} e^{+q_{j} z}-i k_{y} C_{44}\left(C_{44} q_{j}^{2}-C_{11} k_{y}^{2}\right) e^{+q_{j} z} ; \quad(j=2,3) \\
M_{3 j}=-C_{12}\left(C_{12}+C_{44}\right)\left(k_{y}\right)^{2} q_{j} e^{+q_{j} z}-q_{j} C_{11}\left(C_{44} q_{j}^{2}-C_{11} k_{y}^{2}\right) e^{+q_{j} z} ;
\end{array}\right.}
\end{gathered}
$$

(c) The $\left(k_{x} \neq 0, k_{y}=0\right)$ mode

$$
\left[N^{-}\right]=\left(\begin{array}{ccc}
0 & N_{12} & N_{13} \\
N_{21} & 0 & 0 \\
0 & N_{32} & N_{33}
\end{array}\right) ; \quad\left\{\begin{array}{l}
N_{1 j}=i k_{x} q_{j}\left(C_{12}+C_{44}\right) e^{+q_{j} z} ; \\
N_{21}=e^{+\left|k_{x}\right| z} ; \\
N_{3 j}=-\left(C_{44} q_{j}^{2}-C_{11} k_{x}^{2}\right) e^{+q_{j} z} ;
\end{array} \quad(j=2,3)\right.
$$




$$
\left[M^{-}\right]=\left(\begin{array}{ccc}
0 & M_{12} & M_{13} \\
M_{21} & 0 & 0 \\
0 & M_{32} & M_{33}
\end{array}\right) ; \quad\left\{\begin{array}{l}
M_{1 j}=i C_{44}\left(C_{12}+C_{44}\right) k_{x} q_{j}^{2} e^{+q_{j} z}-i k_{x} C_{44}\left(C_{44} q_{j}^{2}-C_{11} k_{x}^{2}\right) e^{+q_{j} z} ; \\
M_{21}=\left|k_{x}\right| C_{44} e^{+\left|k_{x}\right| z} ; \\
M_{3 j}=-C_{12}\left(C_{12}+C_{44}\right) k_{x}^{2} q_{j} e^{+q_{j} z}-q_{j} C_{11}\left(C_{44} q_{j}^{2}-C_{11} k_{x}^{2}\right) e^{+q_{j} z} ;
\end{array} \quad(j=2,3)\right.
$$

\section{APPENDIX B: $M$ AND $N$ MATRIXES IN UPPER SEMI INFINITE SPACE}

(a) The $\left(k_{x} \neq 0, k_{y} \neq 0\right)$ mode

$$
\begin{gathered}
\left\{\begin{array}{l}
\xi_{j}=\left(-k_{y}^{2} C_{11}-k_{x}^{2} C_{44}+q_{j}^{2} C_{44}\right)\left(q_{j}^{2} C_{11}-k_{x}^{2} C_{44}-k_{y}^{2} C_{44}\right)+k_{y}^{2} q_{j}^{2}\left(C_{12}+C_{44}\right)^{2} ; \\
\eta_{j}=-k_{x} k_{y} q_{j}^{2}\left(C_{12}+C_{44}\right)^{2}+k_{x} k_{y}\left(C_{12}+C_{44}\right)\left(q_{j}^{2} C_{11}-k_{x}^{2} C_{44}-k_{y}^{2} C_{44}\right) ; \\
\zeta_{j}=i k_{x} k_{y}^{2} q_{j}\left(C_{12}+C_{44}\right)^{2}+i k_{x} q_{j}\left(C_{12}+C_{44}\right)\left(-k_{y}^{2} C_{11}-k_{x}^{2} C_{44}+q_{j}^{2} C_{44}\right) ;
\end{array} \quad(j=1,2,3)\right. \\
{\left[N^{+}\right]=\left(\begin{array}{lll}
N_{11} & N_{12} & N_{13} \\
N_{21} & N_{22} & N_{23} \\
N_{31} & N_{32} & N_{33}
\end{array}\right) ; \quad \begin{array}{l}
N_{1 j}=\xi_{j} e^{-q_{j} z} ; \\
N_{2 j}=\eta_{j} e^{-q_{j} z} ; \quad(j=1,2,3) \\
N_{3 j}=\zeta_{j} e^{-q_{j} z} ;
\end{array} \quad(j=1,2,3)} \\
{\left[M^{+}\right]=\left(\begin{array}{lll}
M_{11} & M_{12} & M_{13} \\
M_{21} & M_{22} & M_{23} \\
M_{31} & M_{32} & M_{33}
\end{array}\right) ; \quad\left\{\begin{array}{l}
M_{1 j}=C_{44}\left(-\xi_{j} q_{j}+i k_{x} \zeta_{j}\right) e^{-q_{j}^{+} z} ; \\
M_{2 j}=C_{44}\left(-\eta_{j} q_{j}+i k_{y} \zeta_{j}\right) e^{-q_{j} z} ; \\
M_{3 j}=\left(i k_{x} C_{12} \xi_{j}+i k_{y} C_{12} \eta_{j}-C_{11} \zeta_{j} q_{j}\right) e^{-q_{j} z} ;
\end{array}\right.}
\end{gathered}
$$

(b) The $\left(k_{x}=0, k_{y} \neq 0\right)$ mode

$$
\begin{gathered}
{\left[N^{+}\right]=\left(\begin{array}{ccc}
N_{11} & 0 & 0 \\
0 & N_{22} & N_{23} \\
0 & N_{32} & N_{33}
\end{array}\right) ; \quad\left\{\begin{array}{l}
N_{11}=e^{-\left|k_{y}\right| z} ; \\
N_{2 j}=i k_{y} q_{j}\left(C_{12}+C_{44}\right) e^{-q_{j} z} ; \quad(j=2,3) \\
N_{3 j}=\left(q_{j}^{2} C_{44}-k_{y}^{2} C_{11}\right) e^{-q_{j} z} ;
\end{array}\right.} \\
{\left[M^{+}\right]=\left(\begin{array}{ccc}
M_{11} & 0 & 0 \\
0 & M_{22} & M_{23} \\
0 & M_{32} & M_{33}
\end{array}\right) ; \quad\left\{\begin{array}{l}
M_{11}=-\left|k_{y}\right| C_{44} e^{-\left|k_{y}\right| z} ; \\
M_{2 j}=-i k_{y} C_{44}\left(C_{12}+C_{44}\right) q_{j}^{2} e^{-q_{j} z}+i k_{y} C_{44}\left(q_{j}^{2} C_{44}-k_{y}^{2} C_{11}\right) e^{-q_{j} z} ; \quad(j=2,3) \\
M_{3 j}=-C_{12}\left(C_{12}+C_{44}\right) k_{y}^{2} q_{j} e^{-q_{j} z}-C_{11} q_{j}\left(q_{j}^{2} C_{44}-k_{y}^{2} C_{11}\right) e^{-q_{j} z} ;
\end{array}\right.}
\end{gathered}
$$

(c) The $\left(k_{x} \neq 0, k_{y}=0\right)$ mode

$$
\begin{gathered}
{\left[N^{+}\right]=\left(\begin{array}{ccc}
0 & N_{12} & N_{13} \\
N_{21} & 0 & 0 \\
0 & N_{32} & N_{33}
\end{array}\right) ; \quad\left\{\begin{array}{l}
N_{1 j}=i k_{x} q_{j}\left(C_{12}+C_{44}\right) e^{-q_{j} z} ; \\
N_{21}=e^{-\left|k_{x}\right| z} ; \\
N_{3 j}=\left(q_{j}^{2} C_{44}-k_{x}^{2} C_{11}\right) e^{-q_{j} z} ;
\end{array} \quad(j=2,3)\right.} \\
{\left[M^{+}\right]=\left(\begin{array}{ccc}
0 & M_{12} & M_{13} \\
M_{21} & 0 & 0 \\
0 & M_{32} & M_{33}
\end{array}\right) ; \quad\left\{\begin{array}{l}
M_{1 j}=-i k_{x} q_{j}^{2} C_{44}\left(C_{12}+C_{44}\right) e^{-q_{j} z}+i k_{x} C_{44}\left(q_{j}^{2} C_{44}-k_{x}^{2} C_{11}\right) e^{-q_{j} z} ; \\
M_{21}=-\left|k_{x}\right| C_{44} e^{-\left|k_{x}\right| z} ; \\
\left.M_{3 j}=-k_{x}^{2} q_{j} C_{12}\left(C_{12}+C_{44}\right) e^{-q_{j} z}-C_{11} q_{j}\left(q_{j}^{2} C_{44}-k_{x}^{2} C_{11}\right) e^{-q_{j} z} ; \quad j=2,3\right)
\end{array}\right.}
\end{gathered}
$$

\section{APPENDIX C: $M$ AND $N$ MATRIXES IN THIN FILM}

(a) The $\left(k_{x} \neq 0, k_{y} \neq 0\right)$ mode

$$
\left\{\begin{array}{l}
\xi_{j}^{S}=\left[-k_{y}^{2} C_{11}-k_{x}^{2} C_{44}+\left(q_{j}^{S}\right)^{2} C_{44}\right]\left[\left(q_{j}^{S}\right)^{2} C_{11}-k_{x}^{2} C_{44}-k_{y}^{2} C_{44}\right]+k_{y}^{2}\left(q_{j}^{S}\right)^{2}+\left(C_{12}+C_{44}\right)^{2} ; \\
\eta_{j}^{S}=-k_{x} k_{y}\left(q_{j}^{S}\right)^{2}\left(C_{12}+C_{44}\right)^{2}+k_{x} k_{y}\left(C_{12}+C_{44}\right)\left[\left(q_{j}^{S}\right)^{2} C_{11}-k_{x}^{2} C_{44}-k_{y}^{2} C_{44}\right] ; \\
\zeta_{j}^{S}=-i k_{x} k_{y}^{2} q_{j}^{S}\left(C_{12}+C_{44}\right)^{2}-i k_{x} q_{j}^{S}\left(C_{12}+C_{44}\right)\left[-k_{y}^{2} C_{11}-k_{x}^{2} C_{44}+\left(q_{j}^{S}\right)^{2} C_{44}\right] ;
\end{array} \quad(j=1,2,3)\right.
$$




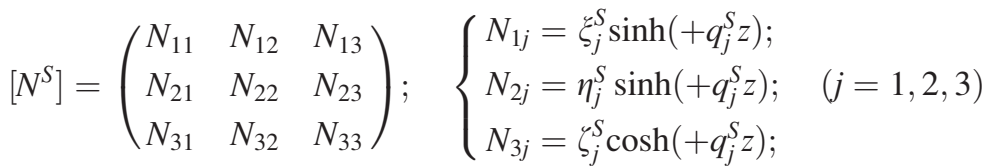

$$
\begin{aligned}
& {\left[M^{S}\right]=\left(\begin{array}{lll}
M_{11} & M_{12} & M_{13} \\
M_{21} & M_{22} & M_{23} \\
M_{31} & M_{32} & M_{33}
\end{array}\right) ; \quad\left\{\begin{array}{l}
M_{1 j}=C_{44}\left(\xi_{j}^{S} q_{j}^{S}+i k_{x} \zeta_{j}^{S}\right) \cosh \left(+q_{j}^{S} z\right) ; \\
M_{2 j}=C_{44}\left(\eta_{j}^{S} q_{j}^{S}+i k_{y} \zeta_{j}^{S}\right) \cosh \left(+q_{j}^{S} z\right) ; \\
M_{3 j}=\left(i k_{x} \xi_{j}^{S} C_{12}+i k_{y} \eta_{j}^{S} C_{12}+q_{j}^{S} \zeta_{j}^{S} C_{11}\right) \sinh \left(+q_{j}^{S} z\right) ;
\end{array} \quad(j=1,2,3)\right.} \\
& \left\{\begin{array}{l}
\xi_{j}^{A}=\left[-k_{y}^{2} C_{11}-k_{x}^{2} C_{44}+\left(q_{j}^{A}\right)^{2} C_{44}\right]\left[\left(q_{j}^{A}\right)^{2} C_{11}-k_{x}^{2} C_{44}-k_{y}^{2} C_{44}\right]+k_{y}^{2}\left(q_{j}^{A}\right)^{2}\left(C_{12}+C_{44}\right)^{2} ; \\
\eta_{j}^{A}=-k_{x} k_{y}\left(q_{j}^{A}\right)^{2}\left(C_{12}+C_{44}\right)^{2}+k_{x} k_{y}\left(C_{12}+C_{44}\right)\left[\left(q_{j}^{A}\right)^{2} C_{11}-k_{x}^{2} C_{44}-k_{y}^{2} C_{44}\right] ; \\
\zeta_{j}^{A}=-i k_{x} k_{y}^{2} q_{j}^{A}\left(C_{12}+C_{44}\right)^{2}-i k_{x} q_{j}^{A}\left(C_{12}+C_{44}\right)\left[-k_{y}^{2} C_{11}-k_{x}^{2} C_{44}+\left(q_{j}^{A}\right)^{2} C_{44}\right]
\end{array} \quad(i=1,2,3)\right.
\end{aligned}
$$

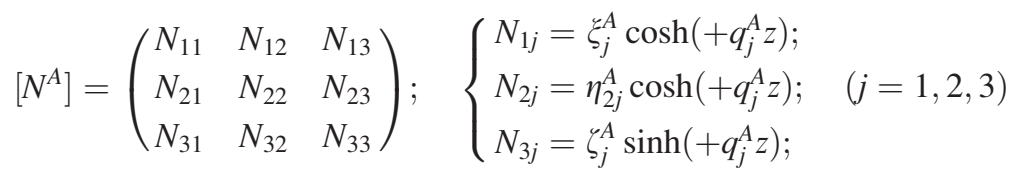

$$
\begin{aligned}
& {\left[M^{A}\right]=\left(\begin{array}{lll}
M_{11} & M_{12} & M_{13} \\
M_{21} & M_{22} & M_{23} \\
M_{31} & M_{32} & M_{33}
\end{array}\right) ; \quad\left\{\begin{array}{l}
M_{1 j}=C_{44}\left(\xi_{j}^{A} q_{j}^{A}+i k_{x} \zeta_{j}^{A}\right) \sinh \left(+q_{j}^{A} z\right) ; \\
M_{2 j}=C_{44}\left(\eta_{j}^{A} q_{j}^{A}+i k_{y} \zeta_{j}^{A}\right) \sinh \left(+q_{j}^{A} z\right) ; \\
M_{3 j}=\left(i k_{x} \xi_{j}^{A} C_{12}+i k_{y} \eta_{j}^{A} C_{12}+q_{j}^{A} \zeta_{j}^{A} C_{11}\right) \cosh \left(+q_{j}^{A} z\right) ;
\end{array} \quad(j=1,2,3)\right.}
\end{aligned}
$$

(b) The $\left(k_{x}=0, k_{y} \neq 0\right)$ mode

$$
\begin{gathered}
{\left[N^{S}\right]=\left(\begin{array}{ccc}
N_{11} & 0 & 0 \\
0 & N_{22} & N_{23} \\
0 & N_{32} & N_{33}
\end{array}\right) ; \quad\left\{\begin{array}{l}
N_{1 j}=\sinh \left(+\left|k_{y}\right| z\right) ; \\
N_{2 j}=i k_{y} q_{j}^{S}\left(C_{12}+C_{44}\right) \sinh \left(+q_{j}^{S} z\right) ; \\
N_{3 j}=-\left[-k_{y}^{2} C_{11}+\left(q_{j}^{S}\right)^{2} C_{44}\right] \cosh \left(+q_{j}^{S} z\right) ;
\end{array} \quad(j=1,2,3)\right.} \\
{\left[M^{S}\right]=\left(\begin{array}{ccc}
M_{11} & 0 & 0 \\
0 & M_{22} & M_{23} \\
0 & M_{32} & M_{33}
\end{array}\right) ;} \\
\left\{\begin{array}{l}
M_{11}=C_{44}\left|k_{y}\right| \cosh \left(+\left|k_{y}\right| z\right) ; \\
\left.\left.M_{2 j}=i C_{44} k_{y}\left(q_{j}^{S}\right)^{2}\left(C_{12}+C_{44}\right) \cosh \left(+q_{j}^{S} z\right)-i C_{44} k_{y}\left[-k_{y}^{2} C_{11}+\left(q_{j}^{S}\right)^{2} C_{44}\right)\right] \cosh \left(+q_{j}^{S} z\right) ; \quad j=1,2,3\right) \\
M_{3 j}=-k_{y}^{2} q_{j}^{S} C_{12}\left(C_{12}+C_{44}\right) \sinh \left(+q_{j}^{S} Z\right)-C_{11} q_{j}^{S}\left[-k_{y}^{2} C_{11}+\left(q_{j}^{S}\right)^{2} C_{44}\right] \sinh \left(+q_{j}^{S} z\right) ; \quad
\end{array}\right. \\
{\left[N^{A}\right]=\left(\begin{array}{ccc}
N_{11} & 0 & 0 \\
0 & N_{22} & N_{23} \\
0 & N_{32} & N_{33}
\end{array}\right) ; \quad\left\{\begin{array}{l}
N_{11}=\cosh \left(+\left|k_{y}\right| z\right) ; \\
N_{2 j}=i k_{y} q_{j}^{A}\left(C_{12}+C_{44}\right) \cosh \left(+q_{j}^{A} z\right) ; \\
N_{3 j}=-\left[\left(q_{j}^{A}\right)^{2} C_{44}-k_{y}^{2} C_{11}\right] \sinh \left(+q_{j}^{A} z\right) ;
\end{array}\right.}
\end{gathered}
$$

$$
\left[M^{A}\right]=\left(\begin{array}{ccc}
M_{11} & 0 & 0 \\
0 & M_{22} & M_{23} \\
0 & M_{32} & M_{33}
\end{array}\right) ;\left\{\begin{array}{l}
M_{11}=\left|k_{y}\right| C_{44} \sinh \left(+\left|k_{y}\right| z\right) ; \\
\left.M_{2 j}=i C_{44} k_{y}\left(q_{j}^{A}\right)^{2}\left(C_{12}+C_{44}\right) \sinh \left(+q_{j}^{A} z\right)-i C_{44} k_{y}\left[\left(q_{j}^{A}\right)^{2} C_{44}-k_{y}^{2} C_{11}\right)\right] \sinh \left(+q_{j}^{A} z\right) ; \quad(j=2,3) \\
M_{3 j}=-k_{y}^{2} C_{12}\left(C_{12}+C_{44}\right) q_{j}^{A} \cosh \left(+q_{j}^{A} Z\right)-C_{11} q_{j}^{A}\left[\left(q_{j}^{A}\right)^{2} C_{44}-k_{y}^{2} C_{11}\right] \cosh \left(+q_{j}^{A} z\right) ;
\end{array}\right.
$$


(c) The $\left(k_{x} \neq 0, k_{y}=0\right)$ mode

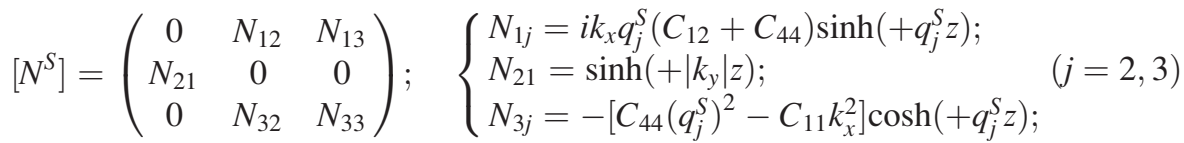

$$
\begin{aligned}
& {\left[M^{S}\right]=\left(\begin{array}{ccc}
0 & M_{12} & M_{13} \\
M_{21} & 0 & 0 \\
0 & M_{32} & M_{33}
\end{array}\right) ; \quad\left\{\begin{array}{l}
M_{1 j}=i k_{x} C_{44}\left(C_{12}+C_{44}\right)\left(q_{j}^{S}\right)^{2} \cosh \left(q_{j}^{S} z\right)-i k_{x} C_{44}\left[C_{44}\left(q_{j}^{S}\right)^{2}-C_{11} k_{x}^{2}\right] \cosh \left(+q_{j}^{S} z\right) ; \\
M_{21}=\left|k_{x}\right| C_{44} \cosh \left(+\left|k_{x}\right| z\right) ; \\
M_{3 j}=-C_{12}\left(C_{12}+C_{44}\right) k_{x}^{2} q_{j}^{S} \sinh \left(q_{j}^{S} Z\right)-C_{11} q_{j}^{S}\left[C_{44}\left(q_{j}^{S}\right)^{2}-C_{11} k_{x}^{2}\right] \sinh \left(+q_{j}^{S} z\right) ;
\end{array}(j=2,3)\right.} \\
& {\left[N^{A}\right]=\left(\begin{array}{ccc}
0 & N_{12} & N_{13} \\
N_{21} & 0 & 0 \\
0 & N_{32} & N_{33}
\end{array}\right) ; \quad\left\{\begin{array}{l}
N_{1 j}=i k_{y} q_{j}^{A}\left(C_{12}+C_{44}\right) \cosh \left(+q_{j}^{A} z\right) ; \\
N_{21}=\cosh \left(+\left|k_{x}\right| z\right) ; \\
N_{3 j}=-\left[\left(q_{j}^{A}\right)^{2} C_{44}-k_{x}^{2} C_{11}\right] \sinh \left(+q_{j}^{A} z\right) ;
\end{array} \quad(j=2,3)\right.} \\
& {\left[M^{A}\right]=\left(\begin{array}{ccc}
0 & M_{12} & M_{13} \\
M_{21} & 0 & 0 \\
0 & M_{32} & M_{33}
\end{array}\right) ; \quad \begin{array}{l}
M_{1 j}=i k_{x} C_{44}\left(C_{12}+C_{44}\right)\left(q_{j}^{A}\right)^{2} \sinh \left(q_{j}^{A} z\right)-i k_{x} C_{44}\left[\left(q_{j}^{A}\right)^{2} C_{44}-k_{x}^{2} C_{11}\right] \sinh \left(+q_{j}^{A} z\right) ; \\
M_{21}=\left|k_{x}\right| C_{44} \cdot \sinh \left(+\left|k_{x}\right| z\right) ; \\
M_{3 j}=-k_{x}^{2} q_{j}^{A} C_{12}\left(C_{12}+C_{44}\right) \cosh \left(q_{j}^{A} z\right)-q_{j}^{A} C_{11}\left[\left(q_{j}^{A}\right)^{2} C_{44}-k_{x}^{2} C_{11}\right] \cosh \left(+q_{j}^{A} z\right) ;
\end{array} \quad(j=2,3)}
\end{aligned}
$$

\section{APPENDIX D: M AND N MATRIXES IN LOWER SEMI INFINITE SPACE WITH [112], [110] AND [111] FREE SURFACE ORIENTATION}

(a) The $\left(k_{x^{\prime}}=0, k_{y^{\prime}} \neq 0\right)$ and $\left(k_{x^{\prime}} \neq 0, k_{y^{\prime}} \neq 0\right)$ mode

$$
\begin{aligned}
& \xi_{j}^{\prime}=\operatorname{det}\left(\begin{array}{ll}
D_{22}^{\prime} & D_{23}^{\prime} \\
D_{32}^{\prime} & D_{33}^{\prime}
\end{array}\right) ; \quad \eta_{j}^{\prime}=\operatorname{det}\left(\begin{array}{cc}
D_{23}^{\prime} & D_{21}^{\prime} \\
D_{33}^{\prime} & D_{31}^{\prime}
\end{array}\right) ; \quad \zeta_{j}^{\prime}=\operatorname{det}\left(\begin{array}{cc}
D_{21}^{\prime} & D_{22}^{\prime} \\
D_{31}^{\prime} & D_{32}^{\prime}
\end{array}\right) \\
& \left\{\begin{array}{l}
D_{11}^{\prime}=\left[-C_{11}^{\prime} k_{x^{\prime}}^{2}+2 i k_{x^{\prime}} q_{j}^{\prime} \cdot C_{16}^{\prime}-C_{55}^{\prime} k_{y^{\prime}}^{2}+\left(q_{j}^{\prime}\right)^{2} \cdot C_{44}^{\prime}\right] ; \\
D_{22}^{\prime}=\left[C_{44}^{\prime}\left(q_{j}^{\prime}\right)^{2}-2 i k_{x^{\prime}} \cdot C_{16}^{\prime} q_{j}^{\prime}-k_{x^{\prime}}^{2} \cdot C_{55}^{\prime}-k_{y^{\prime}}^{2} \cdot C_{11}^{\prime}\right] ; \\
D_{33}^{\prime}=\left[-k_{y^{\prime}}^{2} \cdot C_{44}^{\prime}-k_{x^{\prime}}^{2} \cdot C_{44}^{\prime}+C_{22}^{\prime}\left(q_{j}^{\prime}\right)^{2}\right] ; \\
D_{23}^{\prime}=D_{32}^{\prime}=\left[i k_{y^{\prime}} \cdot C_{44}^{\prime} q_{j}^{\prime}+2 k_{x^{\prime}} k_{y^{\prime}} \cdot C_{16}^{\prime}+i k_{y^{\prime}} q_{j}^{\prime} \cdot C_{12}^{\prime}\right] ; \\
D_{13}^{\prime}=D_{31}^{\prime}=\left[-k_{x^{\prime}}^{2} \cdot C_{16}^{\prime}+i k_{x^{\prime}} \cdot C_{44}^{\prime} q_{j}^{\prime}+i k_{x^{\prime}}^{\prime} q_{j}^{\prime} \cdot C_{12}^{\prime}+k_{y^{\prime}}^{2} \cdot C_{16}^{\prime}\right] ; \\
D_{12}^{\prime}=D_{21}^{\prime}=\left[-i k_{y^{\prime}} \cdot C_{16}^{\prime} q_{j}^{\prime}-k_{x^{\prime}} k_{y^{\prime}} \cdot C_{55}^{\prime}-k_{y^{\prime}} k_{x^{\prime}} \cdot C_{13}^{\prime}-i k_{y^{\prime}} q_{j}^{\prime} \cdot C_{16}^{\prime}\right] ;
\end{array}\right.
\end{aligned}
$$

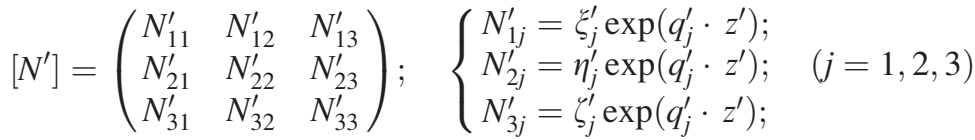

$$
\begin{aligned}
& {\left[M^{\prime}\right]=\left(\begin{array}{lll}
M_{11}^{\prime} & M_{12}^{\prime} & M_{13}^{\prime} \\
M_{21}^{\prime} & M_{22}^{\prime} & M_{23}^{\prime} \\
M_{31}^{\prime} & M_{32}^{\prime} & M_{33}^{\prime}
\end{array}\right) ; \quad\left\{\begin{array}{l}
M_{1 j}^{\prime}=\left[i k_{x^{\prime}} \cdot \xi_{j} C_{16}^{\prime}+q_{j}^{\prime} \cdot \xi_{j} C_{44}^{\prime}-i k_{y^{\prime}} \cdot \eta_{j} C_{16}^{\prime}+i k_{x^{\prime}} \cdot \zeta_{j} C_{44}^{\prime}\right] \cdot \exp \left(q_{j}^{\prime} \cdot z^{\prime}\right) ; \\
M_{2 j}^{\prime}=\left[q_{j}^{\prime} \cdot \eta_{j} C_{44}^{\prime}+i k_{y^{\prime}} \cdot \xi_{j} C_{44}^{\prime}-i k_{x^{\prime}} \cdot \eta_{j} C_{16}^{\prime}-i k_{y^{\prime}} \cdot \xi_{j} C_{16}^{\prime}\right] \cdot \exp \left(q_{j}^{\prime} \cdot z^{\prime}\right) ; \quad(j=1,2,3) \\
M_{3 j}^{\prime}=\left[i k_{x^{\prime}} \cdot \xi_{j} C_{12}^{\prime}+i k_{y^{\prime}} \cdot \eta_{j} C_{12}^{\prime}+q_{j}^{\prime} \cdot \zeta_{j} C_{22}^{\prime}\right] \cdot \exp \left(q_{j}^{\prime} \cdot z^{\prime}\right) ;
\end{array}\right.}
\end{aligned}
$$

(b) The $\left(k_{x^{\prime}} \neq 0, k_{y^{\prime}}=0\right)$ mode

$$
\left[N^{\prime}\right]=\left(\begin{array}{ccc}
0 & N_{12}^{\prime} & N_{13}^{\prime} \\
N_{21}^{\prime} & 0 & 0 \\
0 & N_{32}^{\prime} & N_{33}^{\prime}
\end{array}\right) ; \quad\left\{\begin{array}{l}
N_{1 j}^{\prime}=\left(i k_{x^{\prime}} \cdot q_{j}^{\prime} C_{44}^{\prime}+i k_{x^{\prime}} \cdot q_{j}^{\prime} C_{12}^{\prime}-k_{x^{\prime}}^{2} \cdot C_{16}^{\prime}\right) \exp \left(+q_{j}^{\prime} \cdot z^{\prime}\right) ; \\
N_{21}^{\prime}=\exp \left(\frac{\left.i k_{x^{\prime}} C_{16}^{\prime}+\left|k_{x^{\prime}}\right| \cdot \sqrt{\left(C_{55}^{\prime} C_{44}^{\prime}-C_{16}^{\prime} C_{16}^{\prime}\right)} \cdot z^{\prime}\right) ; \quad C_{44}^{\prime}}{N_{3 j}^{\prime}=-\left[C_{44}^{\prime}\left(q_{j}^{\prime}\right)^{2}+2 i k_{x^{\prime}} C_{16}^{\prime} q_{j}^{\prime}-k_{x^{\prime}}^{2} \cdot C_{11}^{\prime}\right] \exp \left(+q_{j}^{\prime} \cdot z^{\prime}\right)} ; \quad(j=2,3)\right.
\end{array}\right.
$$




$$
\left[M^{\prime}\right]=\left(\begin{array}{ccc}
0 & M_{12}^{\prime} & M_{13}^{\prime} \\
M_{21}^{\prime} & 0 & 0 \\
0 & M_{32}^{\prime} & M_{33}^{\prime}
\end{array}\right) ;\left\{\begin{array}{l}
M_{1 j}^{\prime}=\left[+i k_{x^{\prime}}\left(q_{j}^{\prime}\right)^{2} C_{44}^{\prime} C_{12}^{\prime}+i k_{x^{\prime}}^{3} \cdot C_{11}^{\prime} C_{44}^{\prime}-k_{x^{\prime}}^{2} q_{j}^{\prime} C_{16}^{\prime} C_{12}^{\prime}-i k_{x^{\prime}}^{3} \cdot C_{16}^{\prime} C_{16}^{\prime}\right] \exp \left(q_{j}^{\prime} \cdot z^{\prime}\right) ; \\
M_{21}^{\prime}=\left(+\left|k_{x^{\prime}}\right| \cdot \sqrt{\left(C_{55}^{\prime} C_{44}^{\prime}-C_{16}^{\prime} C_{16}^{\prime}\right)}\right) \exp \left(+\frac{\left.i k_{x^{\prime}} C_{16}^{\prime}+\left|k_{x^{\prime}}\right| \cdot \sqrt{\left(C_{55}^{\prime} C_{44}^{\prime}-C_{16}^{\prime} C_{16}^{\prime}\right)} z\right) ;(j=2,3)}{C_{44}^{\prime}}\right. \\
M_{3 j}^{\prime}=\left[\begin{array}{c}
-k_{x^{\prime}}^{2} q_{j}^{\prime} \cdot C_{12}^{\prime} C_{44}^{\prime}-k_{x^{\prime}}^{2} q_{j}^{\prime} \cdot C_{12}^{\prime} C_{12}^{\prime}-i k_{x^{\prime}}^{3} \cdot C_{12}^{\prime} C_{16}^{\prime} \\
-\left(q_{j}^{\prime}\right)^{3} C_{22}^{\prime} C_{44}^{\prime}-2 i k_{x^{\prime}}\left(q_{j}^{\prime}\right)^{2} C_{22}^{\prime} C_{16}^{\prime}+k_{x^{\prime}}^{2} q_{j}^{\prime} \cdot C_{22}^{\prime} C_{11}^{\prime}
\end{array}\right] \exp \left(q_{j}^{\prime} \cdot z^{\prime}\right) ;
\end{array}\right.
$$

\section{APPENDIX E: M AND N MATRIXES IN THIN FILM WITH [112] , [110] AND [111] FREE SURFACE ORIENTATION}

(a) The $\left(k_{x^{\prime}}=0, k_{y^{\prime}} \neq 0\right)$ and $\left(k_{x^{\prime}} \neq 0, k_{y^{\prime}} \neq 0\right)$ mode

$$
\begin{aligned}
& (\xi)^{S}=\operatorname{det}\left(\begin{array}{ll}
\left(D_{22}^{\prime}\right)^{S} & \left(D_{23}^{\prime}\right)^{S} \\
\left(D_{32}^{\prime}\right)^{S} & \left(D_{33}^{\prime}\right)^{S}
\end{array}\right) ; \quad\left(\eta_{j}^{\prime}\right)^{S}=\operatorname{det}\left(\begin{array}{ll}
\left(D_{23}^{\prime}\right)^{S} & \left(D_{21}^{\prime}\right)^{S} \\
\left(D_{33}^{\prime}\right)^{S} & \left(D_{31}^{\prime}\right)^{S}
\end{array}\right) ; \quad\left(\zeta_{j}^{\prime}\right)^{S}=\operatorname{det}\left(\begin{array}{cc}
\left(D_{21}^{\prime}\right)^{S} & \left(D_{22}^{\prime}\right)^{S} \\
\left(D_{31}^{\prime}\right)^{S} & \left(D_{32}^{\prime}\right)^{S}
\end{array}\right) ; \\
& \left\{\begin{array}{l}
\left(D_{11}^{\prime}\right)^{s}=\left[-C_{11}^{\prime} k_{x^{\prime}}^{2}-C_{55}^{\prime} k_{y^{\prime}}^{2}+2 i k_{x^{\prime}}\left(q_{j}^{\prime}\right)^{s} \cdot C_{16}^{\prime}+\left(\left(q_{j}^{\prime}\right)^{s}\right)^{2} \cdot C_{44}^{\prime}\right] \\
\left(D_{22}^{\prime}\right)^{s}=\left[C_{44}^{\prime}\left(\left(q_{j}^{\prime}\right)^{s}\right)^{2}-2 i k_{x^{\prime}} \cdot C_{16}^{\prime}\left(q_{j}^{\prime}\right)^{s}-k_{x^{\prime}}^{2} \cdot C_{55}^{\prime}-k_{y^{\prime}}^{2} \cdot C_{11}^{\prime}\right] ; \\
\left(D_{33}^{\prime}\right)^{S}=\left[-k_{y^{\prime}}^{2} \cdot C_{44}^{\prime}-k_{x^{\prime}}^{2} \cdot C_{44}^{\prime}+C_{22}^{\prime}\left(\left(q_{j}^{\prime}\right)^{S}\right)^{2}\right] ; \\
\left(D_{23}^{\prime}\right)^{S}=\left(D_{32}^{\prime}\right)^{s}=\left[i k_{y^{\prime}} \cdot C_{44}^{\prime}\left(q_{j}^{\prime}\right)^{S}+2 k_{x^{\prime}} k_{y^{\prime}} \cdot C_{16}^{\prime}+i k_{y^{\prime}}\left(q_{j}^{\prime}\right)^{S} \cdot C_{22}^{\prime}\right] ; \\
\left(D_{13}^{\prime}\right)^{S}=\left(D_{31}^{\prime}\right)^{S}=\left[-k_{x^{\prime}}^{2} \cdot C_{16}^{\prime}+k_{x^{\prime}} \cdot C_{44}^{\prime}\left(q_{j}^{\prime}\right)^{S}+i k_{x^{\prime}}\left(q_{j}^{\prime}\right)^{S} \cdot C_{12}^{\prime}+k_{y^{\prime}}^{2} \cdot C_{16}^{\prime}\right] \\
\left(D_{12}^{\prime}\right)^{S}=\left(D_{21}^{\prime}\right)^{S}=\left[-i k_{y^{\prime}} \cdot C_{16}^{\prime}\left(q_{j}^{\prime}\right)^{S}-k_{x^{\prime}} k_{y^{\prime}} \cdot C_{55}^{\prime}-k_{x^{\prime}} k_{y^{\prime}} \cdot C_{13}^{\prime}-i k_{y^{\prime}}\left(q_{j}^{\prime}\right)^{S} \cdot C_{16}^{\prime}\right]
\end{array}\right.
\end{aligned}
$$

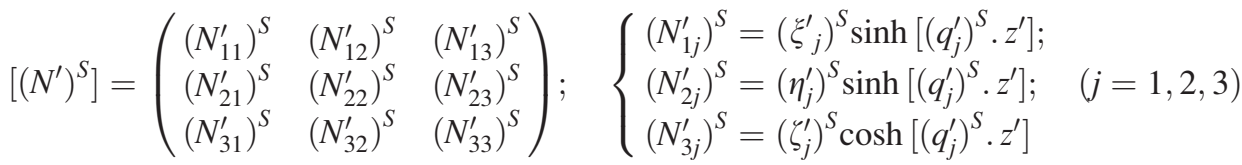

$$
\begin{aligned}
& {\left[\left(M^{\prime}\right)^{s}\right]=\left(\begin{array}{lll}
\left(M_{11}^{\prime}\right)^{s} & \left(M_{12}^{\prime}\right)^{s} & \left(M_{13}^{\prime}\right)^{s} \\
\left(M_{21}^{\prime}\right)^{s} & \left(M_{22}^{\prime}\right)^{s} & \left(M_{23}^{\prime}\right)^{s} \\
\left(M_{31}^{\prime}\right)^{s} & \left(M_{32}^{\prime}\right)^{s} & \left(M_{33}^{\prime}\right)^{s}
\end{array}\right)} \\
& \left\{\begin{array}{l}
\left(M_{1 j}^{\prime}\right)^{s}=\left[i k_{x^{\prime}} \cdot\left(\xi_{j}^{\prime}\right)^{s} C_{16}^{\prime}+\left(q_{j}^{\prime}\right)^{s} \cdot\left(\xi_{j}^{\prime}\right)^{s} C_{44}^{\prime}-i k_{y^{\prime}} \cdot\left(\eta_{j}^{\prime}\right)^{s} C_{16}^{\prime}+i k_{x^{\prime}} \cdot\left(\zeta_{j}^{\prime}\right)^{S} C_{44}^{\prime}\right] \cosh \left[\left(q_{j}^{\prime}\right)^{s} \cdot z\right] ; \\
\left(M_{2 j}^{\prime}\right)^{s}=\left[\left(q_{j}^{\prime}\right)^{s} \cdot\left(\eta_{j}^{\prime}\right)^{s} C_{44}^{\prime}-i k_{y^{\prime}}\left(\zeta_{j}^{\prime}\right)^{s} C_{44}-i k_{x^{\prime}} \cdot\left(\eta_{j}^{\prime}\right)^{s} C_{16}^{\prime}-i k_{y^{\prime}} \cdot\left(\xi_{j}^{\prime}\right)^{S} C_{16}^{\prime}\right] \cosh \left[\left(q_{j}^{\prime}\right)^{s} \cdot z\right] ; \quad(j=1,2,3) \\
\left(M_{3 j}^{\prime}\right)^{s}=\left[i k_{x^{\prime}} \cdot\left(\xi_{j}^{\prime}\right)^{s} C_{12}^{\prime}+i k_{y^{\prime}} \cdot\left(\eta_{j}^{\prime}\right)^{s} C_{12}^{\prime}+\left(q_{j}^{\prime}\right) \cdot\left(\zeta_{j}^{\prime}\right)^{S} C_{22}^{\prime}\right] \sinh \left[\left(q_{j}^{\prime}\right)^{s} \cdot z\right] ;
\end{array}\right.
\end{aligned}
$$

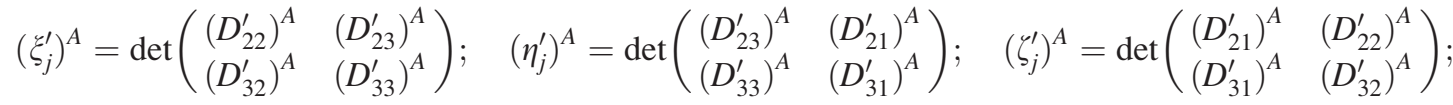

$$
\begin{aligned}
& \left\{\begin{array}{l}
\left(D_{11}^{\prime}\right)^{A}=\left[-C_{11}^{\prime} k_{x^{\prime}}^{2}-C_{55}^{\prime} k_{y^{\prime}}^{2}+2 i k_{x^{\prime}}\left(q_{j}^{\prime}\right)^{A} \cdot C_{16}^{\prime}+\left(\left(q_{j}^{\prime}\right)^{A}\right)^{2} \cdot C_{44}^{\prime}\right] \\
\left(D_{22}^{\prime}\right)^{A}=\left[C_{44}^{\prime}\left(\left(q_{j}^{\prime}\right)^{A}\right)^{2}-2 i k_{x^{\prime}} \cdot C_{16}^{\prime}\left(q_{j}^{\prime}\right)^{A}-k_{x^{\prime}}^{2} \cdot C_{55}^{\prime}-k_{y^{\prime}}^{2} \cdot C_{11}^{\prime}\right] \\
\left(D_{33}^{\prime}\right)^{A}=\left[-k_{y^{\prime}}^{2} \cdot C_{44}^{\prime}-k_{x^{\prime}}^{2} \cdot C_{44}^{\prime}+C_{22}^{\prime}\left(\left(q_{j}^{\prime}\right)^{A}\right)^{2}\right] ; \\
\left(D_{23}^{\prime}\right)^{A}=\left(D_{32}^{\prime}\right)^{A}=\left[i k_{y^{\prime}} \cdot C_{44}^{\prime}\left(q_{j}^{\prime}\right)^{A}+2 k_{x^{\prime}} k_{y^{\prime}} \cdot C_{16}^{\prime}+i k_{y^{\prime}}\left(q_{j}^{\prime}\right)^{A} \cdot C_{12}^{\prime}\right] \\
\left(D_{13}^{\prime}\right)^{A}=\left(D_{31}^{\prime}\right)^{A}=\left[-k_{x^{\prime}}^{2} \cdot C_{16}^{\prime}+i k_{x^{\prime}} \cdot C_{44}^{\prime}\left(q_{j}^{\prime}\right)^{A}+i k_{x^{\prime}}\left(q_{j}^{\prime}\right) \cdot C_{12}^{\prime}+k_{y^{\prime}}^{2} \cdot C_{16}^{\prime}\right] \\
\left(D_{12}^{\prime}\right)^{A}=\left(D_{21}^{\prime}\right)^{A}=\left[-i k_{y^{\prime}} \cdot C_{16}^{\prime}\left(q_{j}^{\prime}\right)^{A}-k_{x^{\prime}} k_{y^{\prime}} \cdot C_{55}^{\prime}-k_{x^{\prime}} k_{y^{\prime}} \cdot C_{13}^{\prime}-i k_{y^{\prime}}\left(q_{j}^{\prime}\right)^{A} \cdot C_{16}^{\prime}\right]
\end{array}\right.
\end{aligned}
$$




$$
\begin{aligned}
& {\left[\left(N^{\prime}\right)^{A}\right]=\left(\begin{array}{lll}
\left(N_{11}^{\prime}\right)^{A} & \left(N_{12}^{\prime}\right)^{A} & \left(N_{13}^{\prime}\right)^{A} \\
\left(N_{21}^{\prime}\right)^{A} & \left(N_{22}^{\prime}\right)^{A} & \left(N_{23}^{\prime}\right)^{A} \\
\left(N_{31}^{\prime}\right)^{A} & \left(N_{32}^{\prime}\right)^{A} & \left(N_{33}^{\prime}\right)^{A}
\end{array}\right) ; \quad\left\{\begin{array}{l}
\left(N_{1 j}^{\prime}\right)^{A}=\left(\xi_{j}^{\prime}\right)^{A} \cosh \left[\left(q_{j}^{\prime}\right)^{A} \cdot z\right] ; \\
\left(N_{2 j}^{\prime}\right)^{A}=\left(\eta_{j}^{\prime}\right)^{A} \cosh \left[\left(q_{j}^{\prime}\right)^{A} \cdot z\right] ; \quad(j=1,2,3) \\
\left(N_{3 j}^{\prime}\right)^{A}=\left(\zeta_{j}^{\prime}\right)^{A} \sinh \left[\left(q_{j}^{\prime}\right)^{A} \cdot z\right] ;
\end{array}\right.} \\
& {\left[\left(M^{\prime}\right)^{A}\right]=\left(\begin{array}{lll}
\left(M_{11}^{\prime}\right)^{A} & \left(M_{12}^{\prime}\right)^{A} & \left(M_{13}^{\prime}\right)^{A} \\
\left(M_{21}^{\prime}\right)^{A} & \left(M_{22}^{\prime}\right)^{A} & \left(M_{23}^{\prime}\right)^{A} \\
\left(M_{31}^{\prime}\right)^{A} & \left(M_{32}^{\prime}\right)^{A} & \left(M_{33}^{\prime}\right)^{A}
\end{array}\right)} \\
& \left\{\begin{array}{l}
\left(M_{1 j}^{\prime}\right)^{A}=\left[i k_{x^{\prime}} \cdot\left(\xi_{j}^{\prime}\right)^{A} C_{16}^{\prime}+\left(q_{j}^{\prime}\right)^{A} \cdot\left(\xi_{j}^{\prime}\right)^{A} C_{44}^{\prime}-i k_{y^{\prime}} \cdot\left(\eta_{j}^{\prime}\right)^{A} C_{16}^{\prime}+i k_{x^{\prime}} \cdot\left(\zeta_{j}^{\prime}\right)^{A} C_{44}^{\prime}\right] \sinh \left[\left(q_{j}^{\prime}\right)^{A} \cdot z\right] ; \\
\left(M_{2 j}^{\prime}\right)^{A}=\left[\left(q_{j}^{\prime}\right)^{A} \cdot\left(\eta_{j}^{\prime}\right)^{A} C_{44}^{\prime}+i k_{y^{\prime}}\left(\zeta_{j}^{\prime}\right)^{A} C_{44}-i k_{x^{\prime}} \cdot\left(\eta_{j}^{\prime}\right)^{A} C_{16}^{\prime}-i k_{y^{\prime}} \cdot\left(\xi_{j}^{\prime}\right)^{A} C_{16}^{\prime}\right] \sinh \left[\left(q_{j}^{\prime}\right)^{A} \cdot z\right] ; \quad(j=1,2,3) \\
\left(M_{3 j}^{\prime}\right)^{A}=\left[i k_{x^{\prime}} \cdot\left(\xi_{j}^{\prime}\right)^{A} C_{12}^{\prime}+i k_{y^{\prime}} \cdot\left(\eta_{j}^{\prime}\right)^{A} C_{12}^{\prime}+\left(q_{j}^{\prime}\right)^{A} \cdot\left(\zeta_{j}^{\prime}\right)^{A} c_{22}^{\prime}\right] \cosh \left[\left(q_{j}^{\prime}\right)^{A} \cdot z\right] ;
\end{array}\right.
\end{aligned}
$$

(b) The $\left(k_{x^{\prime}} \neq 0, k_{y^{\prime}}=0\right)$ mode

$$
\begin{aligned}
& {\left[\left(N^{\prime}\right)^{S}\right]=\left(\begin{array}{ccc}
0 & \left(N_{12}^{\prime}\right)^{S} & \left(N_{13}^{\prime}\right)^{S} \\
\left(N_{21}^{\prime}\right)^{S} & 0 & 0 \\
0 & \left(N_{32}^{\prime}\right)^{S} & \left(N_{33}^{\prime}\right)^{S}
\end{array}\right) ; \quad\left\{\begin{array}{l}
\left(N_{1 j}^{\prime}\right)^{S}=\left(i k_{x^{\prime}} \cdot\left(q_{j}^{\prime}\right)^{S} C_{44}^{\prime}+i k_{x^{\prime}} \cdot\left(q_{j}^{\prime}\right)^{S} C_{12}^{\prime}-k_{x^{\prime}}^{2} \cdot C_{16}^{\prime}\right) \sinh \left(+\left(q_{j}^{\prime}\right)^{S} \cdot z^{\prime}\right) ; \\
\left(N_{21}^{\prime}\right)^{S}=\sinh \left(\frac{i k_{x^{\prime}} C_{16}^{\prime}+\left|k_{x^{\prime}}\right| \cdot \sqrt{\left(C_{55}^{\prime} C_{44}^{\prime}-C_{16}^{\prime} C_{16}^{\prime}\right)}}{C_{44}^{\prime}} \cdot z^{\prime}\right) ; \\
\left(N_{3 j}^{\prime}\right)^{S}=-\left[C_{44}^{\prime}\left(\left(q_{j}^{\prime}\right)^{2}\right)^{S}+2 i k_{x^{\prime}} C_{16}^{\prime}\left(q_{j}^{\prime}\right)^{S}-k_{x^{\prime}}^{2} \cdot C_{11}^{\prime}\right] \cosh \left(+\left(q_{j}^{\prime}\right)^{S} \cdot z^{\prime}\right)
\end{array}\right.} \\
& {\left[\left(M^{\prime}\right)^{S}\right]=\left(\begin{array}{ccc}
0 & \left(M_{12}^{\prime}\right)^{S} & \left(M_{13}^{\prime}\right)^{S} \\
\left(M_{21}^{\prime}\right)^{S} & 0 & 0 \\
0 & \left(M_{32}^{\prime}\right)^{S} & \left(M_{33}^{\prime}\right)^{S}
\end{array}\right) ;} \\
& \left\{\begin{array}{l}
\left(M_{1 j}^{\prime}\right)^{S}=\left[+i k_{x^{\prime}}\left(\left(q_{j}^{\prime}\right)^{S}\right)^{2} C_{44}^{\prime} C_{12}^{\prime}+i k_{x^{\prime}}^{3} \cdot C_{11}^{\prime} C_{44}^{\prime}-k_{x^{\prime}}^{2}\left(q_{j}^{\prime}\right)^{S} C_{16}^{\prime} C_{12}^{\prime}-i k_{x^{\prime}}^{3} \cdot C_{16}^{\prime} C_{16}^{\prime}\right] \cosh \left(\left(q_{j}^{\prime}\right)^{S} \cdot z^{\prime}\right) \\
\left(M_{21}^{\prime}\right)^{S}=\left(+\left|k_{x^{\prime}}\right| \cdot \sqrt{\left(C_{55}^{\prime} C_{44}^{\prime}-C_{16}^{\prime} C_{16}^{\prime}\right)}\right) \cosh \left(+\frac{\left.i k_{x^{\prime}} C_{16}^{\prime}+\left|k_{x^{\prime}}\right| \cdot \sqrt{\left(C_{55}^{\prime} C_{44}^{\prime}-C_{16}^{\prime} C_{16}^{\prime}\right)} z\right)}{C_{44}^{\prime}} z \quad(j=2,3)\right. \\
M_{3 j}^{\prime}=\left[\begin{array}{l}
-k_{x^{\prime}}^{2}\left(q_{j}^{\prime}\right)^{S} \cdot C_{12}^{\prime} C_{44}^{\prime}-k_{x^{\prime}}^{2}\left(q_{j}^{\prime}\right)^{S} \cdot C_{12}^{\prime} C_{12}^{\prime}-i k_{x^{\prime}}^{3} \cdot C_{12}^{\prime} C_{16}^{\prime} \\
-\left(\left(q_{j}^{\prime}\right)^{S}\right)^{3} C_{22}^{\prime} C_{44}^{\prime}-2 i k_{x^{\prime}}\left(\left(q_{j}^{\prime}\right)^{S}\right)^{2} C_{22}^{\prime} C_{16}^{\prime}+k_{x^{\prime}}^{2}\left(q_{j}^{\prime}\right)^{S} \cdot C_{22}^{\prime} C_{11}^{\prime}
\end{array}\right] \sinh \left(\left(q_{j}^{\prime}\right)^{S} \cdot z^{\prime}\right)
\end{array}\right.
\end{aligned}
$$

$$
\begin{aligned}
{\left[\left(N^{\prime}\right)^{A}\right]=} & \left(\begin{array}{ccc}
0 & \left(N_{12}^{\prime}\right)^{A} & \left(N_{13}^{\prime}\right)^{A} \\
\left(N_{21}^{\prime}\right)^{A} & 0 & 0 \\
0 & \left(N_{32}^{\prime}\right)^{A} & \left(N_{33}^{\prime}\right)^{A}
\end{array}\right) ; \\
& \left\{\begin{array}{l}
\left(N_{1 j}^{\prime}\right)^{A}=\left(i k_{x^{\prime}} \cdot\left(q_{j}^{\prime}\right)^{A} C_{44}^{\prime}+i k_{x^{\prime}} \cdot\left(q_{j}^{\prime}\right)^{A} C_{12}^{\prime}-k_{x^{\prime}}^{2} \cdot C_{16}^{\prime}\right) \cosh \left(+\left(q_{j}^{\prime}\right)^{A} \cdot z^{\prime}\right) ; \\
\left(N_{21}^{\prime}\right)^{A}=\cosh \left(\frac{i k_{x^{\prime}} C_{16}^{\prime}+\left|k_{x^{\prime}}\right| \cdot \sqrt{\left(C_{55}^{\prime} C_{44}^{\prime}-C_{16}^{\prime} C_{16}^{\prime}\right)}}{C_{44}^{\prime}} \cdot z^{\prime}\right. \\
\left(N_{3 j}^{\prime}\right)^{A}=-\left[C_{44}^{\prime}\left(\left(q_{j}^{\prime}\right)^{A}\right)^{2}+2 i k_{x^{\prime}} C_{16}^{\prime}\left(q_{j}^{\prime}\right)^{A}-k_{x^{\prime}}^{2} \cdot C_{11}^{\prime}\right] \sinh \left(+\left(q_{j}^{\prime}\right)^{A} \cdot z^{\prime}\right)
\end{array}\right.
\end{aligned}
$$




$$
\begin{aligned}
& {\left[\left(M^{\prime}\right)^{A}\right]=\left(\begin{array}{ccc}
0 & \left(M_{12}^{\prime}\right)^{A} & \left(M_{13}^{\prime}\right)^{A} \\
\left(M_{21}^{\prime}\right)^{A} & 0 & 0 \\
0 & \left(M_{32}^{\prime}\right)^{A} & \left(M_{33}^{\prime}\right)^{A}
\end{array}\right)} \\
& \left\{\begin{array}{l}
\left(M_{1 j}^{\prime}\right)^{A}=\left[+i k_{x^{\prime}}\left(\left(q_{j}^{\prime}\right)^{A}\right)^{2} C_{44}^{\prime} C_{12}^{\prime}+i k_{x^{\prime}}^{3} \cdot C_{11}^{\prime} C_{44}^{\prime}-k_{x^{\prime}}^{2}\left(q_{j}^{\prime}\right)^{A} C_{16}^{\prime} C_{12}^{\prime}-i k_{x^{\prime}}^{3} \cdot C_{16}^{\prime} C_{16}^{\prime}\right] \sinh \left(\left(q_{j}^{\prime}\right)^{A} \cdot z^{\prime}\right) ; \\
\left.\left(M_{21}^{\prime}\right)^{A}=\left(+\left|k_{x^{\prime}}\right| \cdot \sqrt{\left(C_{55}^{\prime} C_{44}^{\prime}-C_{16}^{\prime} C_{16}^{\prime}\right)}\right) \sinh \left(+\frac{\left.i k_{x^{\prime}} C_{16}^{\prime}+\left|k_{x^{\prime}}\right| \cdot \sqrt{\left(C_{55}^{\prime} C_{44}^{\prime}-C_{16}^{\prime} C_{16}^{\prime}\right)} z\right) ;}{C_{44}^{\prime}}\right) ;=2,3\right) \\
\left(M_{3 j}^{\prime}\right)^{A}=\left[\begin{array}{l}
-k_{x^{\prime}}^{2}\left(q_{j}^{\prime}\right)^{A} \cdot C_{12}^{\prime} C_{44}^{\prime}-k_{x^{\prime}}^{2}\left(q_{j}^{\prime}\right)^{A} \cdot C_{12}^{\prime} C_{12}^{\prime}-i k_{x^{\prime}}^{3} \cdot C_{12}^{\prime} C_{16}^{\prime} \\
-\left(\left(q_{j}^{\prime}\right)^{A}\right)^{3} C_{22}^{\prime} C_{44}^{\prime}-2 i k_{x^{\prime}}\left(\left(q_{j}^{\prime}\right)^{A}\right)^{2} C_{22}^{\prime} C_{16}^{\prime}+k_{x^{\prime}}^{2}\left(q_{j}^{\prime}\right)^{A} \cdot C_{22}^{\prime} C_{11}^{\prime}
\end{array}\right] \cosh \left(\left(q_{j}^{\prime}\right)^{A} \cdot z^{\prime}\right) ;
\end{array}\right.
\end{aligned}
$$

${ }^{1}$ S. M. Ohr, J. Appl. Phys. 49(9), 4953 (1978).

${ }^{2}$ C. L. Kelchner, S. J. Plimpton, and J. C. Hamilton, Phys. Rev. B 58, 11085 (1998).

${ }^{3}$ T. A. Khraishi, H. M. Zbib, and T. D. de la Rubia, Mater. Sci. Eng., A 309-310, 283 (2001).

${ }^{4}$ W. Cai, V. V. Bulatob, J. Chang, J. Li, and S. Yip, Philos. Mag. 83(5), 539 (2003).

${ }^{5}$ L. Yan, T. A. Khraishi, Y.-L. Shen, and M. F. Horstemeyer, Modell. Simul. Mater. Sci. Eng. 12, 289 (2004).

${ }^{6}$ S. Aubry, S. P. Fitzgerald, S. L. Dudarev, and W. Cai, Modell. Simul. Mater. Sci. Eng. 19, 065006 (2011)

${ }^{7}$ A. K. Head, Proc. Phys. Soc., London, Sect. B 66, 793 (1953).

${ }^{8}$ C.-L. Lee and S. Li, Acta Mater. 55, 2149-2157 (2007).

${ }^{9}$ C.-L. Lee and S. Li, Math. Mech. Solids 13, 316-335 (2008).

${ }^{10}$ A. Hartmaier, M. C. Fivel, G. R. Canova, and P. Gumbsch, Modell. Simul. Mater. Sci. Eng. 7, 781 (1999).

${ }^{11}$ T. Mori and K. Tanaka, Acta Metall. 21, 571 (1973).

${ }^{12}$ J. Lothe, V. L. Indenbom, and V. A. Chamrov, Phys. Status Solidi B 111, 671 (1982).

${ }^{13}$ P. P. Groves and D. J. Bacon, Philos. Mag. 22, 83 (1970).

${ }^{14}$ M. C. Fivel, T. J. Goslingz, and G. R. Canova, Modell. Simul. Mater. Sci. Eng. 4, 581 (1996).
${ }^{15}$ E. van der Giessen and A. Needleman, American Society of Mechanical Engineers (Aerospace Division, 1994), Vol. 42, p. 53.

${ }^{16}$ R. Martinez and N. M. Ghoniem, J. Comput. Methods Eng. Sci, CMES 3(2), 229 (2002)

${ }^{17}$ M. Tang, G. Xu, W. Cai, and V. V. Bulatov, Mater. Res. Soc. Symp. Proc. 795, U.2.4.1 (2004).

${ }^{18}$ P. Khanikar et al., Adv. Mater. Res. 67, 33 (2009).

${ }^{19}$ C. R. Weinberger, S. Aubry, S.-W. Lee, W. D. Nix, and W. Cai, Modell. Simul. Mater. Sci. Eng. 17, 075007 (2009).

${ }^{20}$ D. M. Barnettt and J. Lothet, J. Phys. F: Met. Phys. 4(10), 1618 (1974).

${ }^{21}$ J. P. Hirth and J. Lothe, Theory of Dislocations, 2nd ed. (Krieger Publishing Company, Malabar, Florida, 1982).

${ }^{22}$ W. Voigt, Ann. Phys. 38, 573 (1889).

${ }^{23}$ A. Reuss, J. Appl. Math. Mech. 9, 49 (1929).

${ }^{24}$ T. Mura, Micromechanics of Defects in Solids, 2nd ed., revised edition (Martinus Nijhoff, 1987).

${ }^{25}$ J. Yin, D. M. Barnett, and W. Cai, Modell. Simul. Mater. Sci. Eng. 18(4), 045013 (2010).

${ }^{26}$ J. A. Dellinger, "Anisotropic seismic wave propagation," Ph.D. dissertation (Standford University, 1991).

${ }^{27}$ D. J. Dever, J. Appl. Phys. 43, 3293 (1972). 